\title{
Center of pressure displacement characteristics differentiate fall risk in older people: A systematic review with meta-analysis
}

\author{
Flavien Quijoux ${ }^{\mathrm{a}, \mathrm{b}, *}$, Aliénor Vienne-Jumeau ${ }^{\mathrm{a}}$, François Bertin-Hugault ${ }^{\mathrm{b}}$, Philippe Zawieja ${ }^{\mathrm{b}}$, \\ Marie Lefèvre $^{\mathrm{b}}$, Pierre-Paul Vidal ${ }^{\mathrm{a}, \mathrm{c}}$, Damien Ricard ${ }^{\mathrm{a}, \mathrm{d}, \mathrm{e}}$ \\ ${ }^{a}$ Centre Borelli UMR 9010/Université Paris-Saclay, ENS Paris-Saclay, CNRS, SSA, Inserm, Université de Paris 45 rue des Saints Pères, 75006 PARIS, France \\ ${ }^{\mathrm{b}}$ ORPEA Group, 12 rue Jean Jaurès, CS 10032, 92813 Puteaux Cedex, France \\ ${ }^{\mathrm{c}}$ Institute of Information and Control, Hangzhou Dianzi University, Zhejiang, 310018, China \\ ${ }^{\mathrm{d}}$ Service de Neurologie de l'Hôpital d'Instruction des Armées de Percy, Service de Santé des Armées, 101 Avenue Henri Barbusse, 92140 Clamart, France \\ ${ }^{\mathrm{e}}$ Ecole du Val-de-Grâce, Ecole de Santé des Armées, 1 Place Alphonse Laveran, 75005 Paris, France
}

\section{A R T I C L E I N F O}

\section{Keywords:}

Older fallers

Quiet standing

Balance

Center of pressure (COP)

Prediction

Risk of falling

\begin{abstract}
A B S T R A C T
Falling is the second most prevalent cause of accidental death in the world. Currently available clinical tests to assess balance in older people are insufficiently sensitive to screen for fall risk in this population. Laboratory tests that record the center of pressure (COP) trajectory could overcome this problem but despite their widespread use, the choice of COP trajectory features for use as a biomarker of fall risk lacks consensus. This systematic review and meta-analysis aimed at identifying the best COP characteristics to predict risk of falling in older adults. More than 4000 articles were screened; 44 (7176 older adults) were included in this study. Several COP parameters emerged as good indices to discriminate fallers from non-fallers. From sensitivity analysis, Sway area per unit time, anteroposterior mean velocity, and radial mean velocity were the best traditional features. In this study, identification of older people with a high fall risk was demonstrated using quiet-standing recordings. Such screening would also be useful for routine follow-up of balance changes in older fallers in clinical practice.
\end{abstract}

\section{Introduction}

Falls in older people are a major issue, representing one of the main causes of injury deaths in this age-group ("WHO global report on falls prevention in older age," 2008). A non-fatal fall can lead to severe injuries such as hip fracture or traumatic brain injury, especially in a population who often also suffer from confounding conditions such as osteoporosis (Resnick et al., 2014) or brain atrophy (Seidler et al., 2010; Sheridan and Hausdorff, 2007; Yamada et al., 2013). The risk of falling is approximately $15 \%$ for people older than age 65 , rising to $25 \%$ for those older than age 80 (HAS, 2009; Rubenstein, 2006). Falls also result in a fear of falling again in the future (Arfken et al., 1994; Murphy and Isaacs, 1982; Vellas et al., 1997) and consequently physiological deconditioning (Iaboni et al., 2015; Malini et al., 2016; Prabhakaran et al., 2019), which itself creates substantial financial healthcare costs (HAS, 2009). For patients, reduced independence increases anxiety, social isolation, psychomotor problems related to the fall, and the subsequent development of any otherwise preventable chronic diseases that result from the traumatic consequences that limit physical activity (Lee et al.,
2007; Pereira et al., 2008).

Estimating the risk of falling could provide guidance for adapting rehabilitation programs and provision of care. The occurrence of falls depends on extrinsic factors in the environment such as insufficient lighting or obstacles, for example, as well as intrinsic factors related to the physical capacities of the individual (Datta et al., 2018; Deandrea et al., 2013). Intrinsic precipitating causes have been associated with up to $80 \%$ of falls recorded in institutionalized older people, with the highest prevalence amongst the oldest people (Bueno-Cavanillas et al., 2000). Intrinsic precipitating causes include a past history of falls (Gerdhem et al., 2005), dementia (Scherder et al., 2007), degeneration and lesions of the visual, vestibular and proprioceptive systems (Goble et al., 2009), gait and balance disorders (Seidler et al., 2010), sarcopenia (Landi et al., 2012), and other musculoskeletal modifications (Álvarez Barbosa et al., 2016; Kinney, 2004), all of which can lead to instabilities in different contexts (Bock and Schneider, 2002; Horak, 2006; Li et al., 2018).

Individual fall-risk factors can be monitored longitudinally and the results used in predictive risk-score calculations (Wihlborg et al., 2015).

\footnotetext{
*Corresponding author at: Centre Borelli UMR 9010/Université Paris-Saclay, ENS Paris-Saclay, CNRS, SSA, Inserm, Université de Paris, 45 rue des Saint-Pères 75006 Paris : http://centreborelli.cnrs.fr/

E-mail address: f.quijoux@orpea.net (F. Quijoux).
} 
However, all fall prevention efforts face the problem that postural control is dependent on the functioning of many underlying interacting systems: vestibular, proprioceptive and visual information merge to provide people with an internal, sensory representation of their body's movement (Horak, 2006; Ricci et al., 2009) while biomechanical properties, such as reflexive mechanisms (Ho and Bendrups, 2002; Srulijes et al., 2015; Suzuki and Geyer, 2018), and cognitive processing (Borel and Alescio-Lautier, 2014; Mahboobin et al., 2008) are factors that are involved in the maintenance of body equilibrium.

The detection of intrinsic fall-risk factors is complicated, especially before any fall has occurred. Solutions are needed, however, to help more easily detect larger numbers of 'future fallers' either in the field (such as at home or in an institution) or in a clinical setting. For this review we have chosen to explore one such potential method: the use of quiet standing posturography. This study was based on our clinical experience to date which led us to believe that routine, detailed and automatic quantification of motor control using posturography at rest, and the monitoring of locomotion by inertial sensors in an elderly population may provide an accessible and reliable indicator of fall risk (Howcroft et al., 2013; Truong et al., 2019).

The possibility that static posturography could detect future fallers before they fall is particularly attractive because, to date, existing clinical tests to detect those at fall risk have only shown limited success (Horak, 1987) and have not provided better identification of future fallers than practitioners' subjective clinical judgments (da Costa et al., 2012) or the fall history questionnaire (Gates et al., 2008). The reasons given for these test failures include: (1) a lack of objectivity and experimenter bias; (2) an inability to identify balance disorders (Mancini and Horak, 2010); (3) an insensitivity to minor changes in balance ability (Downs et al., 2013; Pajala et al., 2008); (4) poor sensitivity or specificity (depending on the particular test) (da Costa et al., 2012); (5) inconsistent test cut-off values between studies (Beauchet et al., 2011; Lima et al., 2018; Schoene et al., 2013; Shumway-Cook et al., 2000); (6) a susceptibility to ceiling effects (Balasubramanian, 2015); (7) test results being unrelated to fall incidence (Barry et al., 2014; Brodie et al., 2017) and (8) the fact that tests take a long time because they are often complicated (Langley et al., 2007; Perell et al., 2001; Vassallo et al., 2008; Zampieri et al., 2010).

Therefore, a test is needed to provide clinicians with objective and reliable measures of balancing abilities, especially for the frailest older adults, which would complement the functional tests already used in clinical practice. We believe that quantitative posturographic tests, which assess balance by recording center of pressure (COP) oscillations (Błaszczyk, 2016), could provide this useful information to complement the functional tests (Mancini and Horak, 2010; Muir et al., 2010).

Sway parameters extracted from posturography data have been shown to correlate with both fall risk factors (Nardone and Schieppati, 2010; Bauer et al., 2010) and deficient postural strategies (Dueñas et al., 2016; Kręcisz and Kuczyński, 2018). In addition, posturography has been proposed as a means of detecting age-related alterations of postural control at sensory (Alcock et al., 2018), central (Nandi et al., 2018; Ozdemir et al., 2018) musculoskeletal levels (King et al., 2019). Among healthy older people who live in the community, balance and sway measurements have been found to be strong predictors of fall risk (Audiffren et al., 2016; Johansson et al., 2017; Piirtola and Era, 2006; Watt et al., 2018). Finally, an objective, instrumental assessment of sway may also be helpful to guide and evaluate the efficiency of rehabilitation programs aiming at reducing the risk of falling (HAS, 2007).

Before continuing with this review, however, it should be noted that the aim is not to establish posturography as a sole means of predicting falls. Despite its encouraging results, posturography also has several short comings to detect future fallers. The first is that rather than occurring during quiet standing, most falls actually happen during locomotor tasks (Talbot et al., 2005) and activities of daily living (van Emmerik and van Wegen, 2002), a fact which limits the wider applicability of COP recordings (Doyle et al., 2005; Ruhe et al., 2010). Secondly, while averaged parameters of the whole COP trajectory have moderate-to-high reliability (Jeter et al., 2015, 2015; Lafond et al., 2004; Li et al., 2016; Lin et al., 2008; Moghadam et al., 2011), the necessary data collection requires long recording periods and several repetitions (Doyle et al., 2007; Lafond, 2006; Ruhe et al., 2010) which would probably make the method inconvenient for everyday clinical practice. Thirdly, to date, the neurophysiological determinants of the various COP parameters are ill-defined (Palmieri et al., 2002; Visser et al., 2008).

In summary, therefore, although there is room for improvement in the use of quiet standing posturography as a tool for the detection the risk of future falls in patients, it is nevertheless worthy of further consideration especially since, at present, it appears to outperform many other tests that are currently being used clinically. The objective of this systematic review, therefore, is to identify the most relevant parameters, conditions and caveats that will allow posturography at rest to be used with the greatest level of confidence to identify fall risk in elderly people.

\section{Methods}

The literature search and analysis followed the Preferred Reporting Items for Systematic Reviews and Meta-Analyses (PRISMA) (Moher et al., 2009) and Meta-analysis of Observational Studies in Epidemiology (MOOSE) (Stroup et al., 2000) guidelines.

\subsection{Literature search strategy}

The search strategy can be found in (Quijoux et al., 2019) and is described in the registration on PROSPERO (International Prospective Register of Systematic Reviews) (Registration: CRD42018098671 on June 19, 2018; last edited on January 17, 2020). The methods for the meta-analysis were specified prior to the completion of the inclusion of studies and the full method has been previously published (Quijoux et al., 2019). Between March 2017 and July 2019, a systematic literature review was conducted to identify COP characteristics that best distinguish older fallers from older non-fallers. Four electronic databases were searched: PubMed, ScienceDirect, EMBASE, and the Cochrane Library. The search was performed for all articles published (without date restriction) until July 1, 2019. In addition, a search of 'gray' literature (Conn et al., 2003) was performed which included items like reports, theses and studies that were found online using Google Scholar, ClinicalTrials.gov sources, Google, theses.fr, HAL, ResearchGates and ethos.bl.uk.

All reference lists from included studies were reviewed for additional relevant studies. Many different types of studies were included, because the aim was not to find a fall reduction intervention but to investigate the discriminative abilities of bipedal quiet stance tests. From all of the sources found, data which related to fall risk in older people (defined as being aged 60 years and older) who had undergone quiet-standing measurement of their balance was used provided that the researchers had used stabilometry to quantify postural control. Sources came from both retrospective and prospective clinical trials (randomization was not a requisite), and observational studies (time series, longitudinal or cross-sectional). The papers had to be written in a language understood by the authors (i.e. English, French, Italian, Spanish or German).

\subsection{Screening process}

Research was considered for inclusion if it contained: (1) a comparison of older fallers and older non-fallers; (2) a record of the number of falls in each group; (3) an analysis of COP recordings during quiet standing for people who had both feet on the ground; (4) an evaluation of the risk of falling using the number of falls retrospectively or 


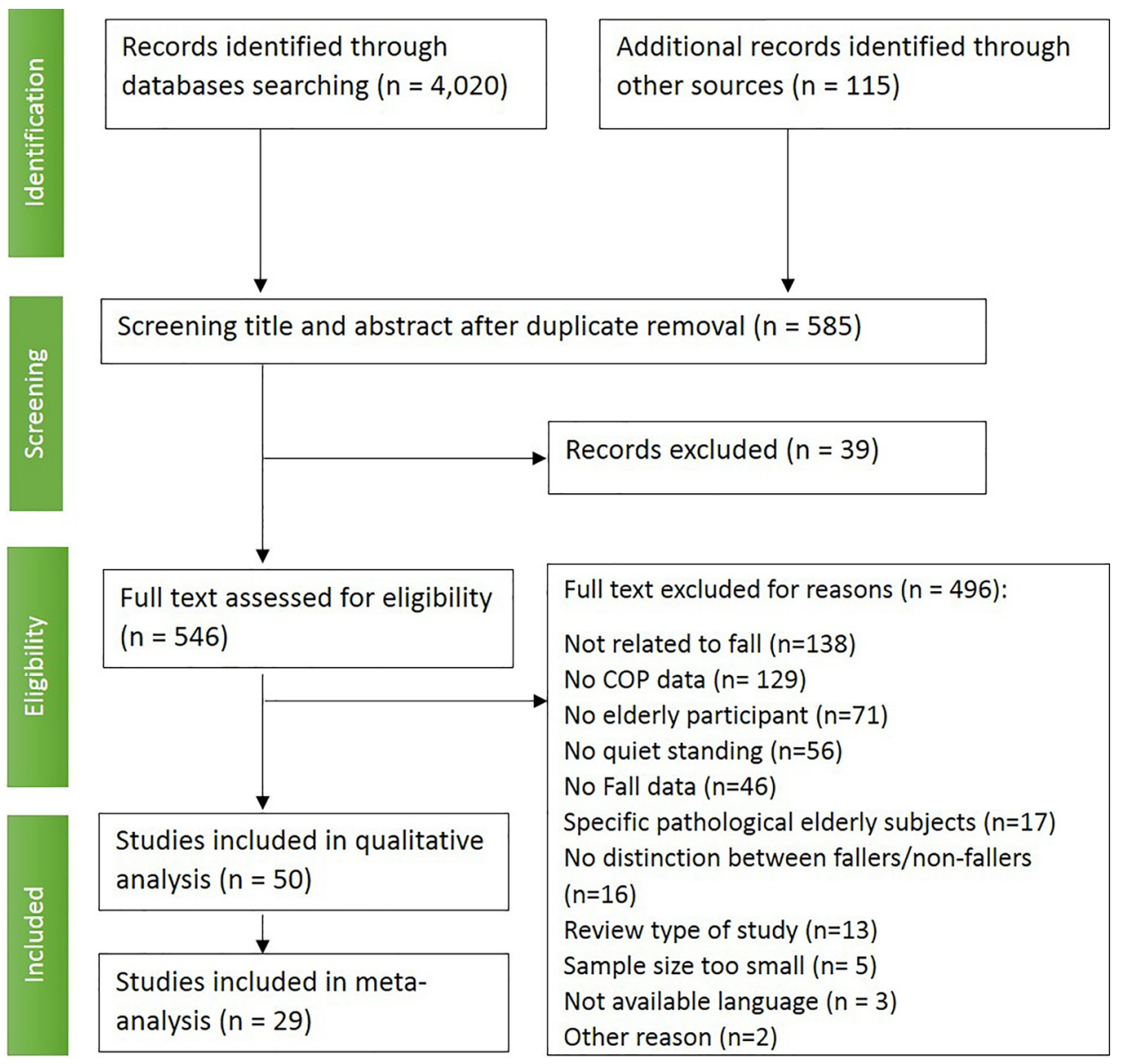

Fig. 1. Flowchart of the systematic review process.

COP: center of pressure

prospectively. Two authors (FQ and AV) independently screened potentially eligible studies for inclusion on the basis of their title, abstract and full text.

FQ and AV performed the risk of bias assessment by using a 26-item checklist based on Downs and Black (1998) (Risk of bias assessment checklist - Supplementary material). This score out of 32 evaluates the risk of bias, with a high value representing low risk. Then, one author (FQ) extracted and collated the data, following the recommendations of the Joanna Briggs Institute Reviewers' Manual (The Joanna Briggs Institute, 2015) while another author (AV) verified the data extracted from the included articles to confirm their suitability. If any study lacked data or information regarding the participants (even after contacting the authors) it was excluded from the meta-analysis.

\subsection{Data pooling strategy}

For pooling predictive data from COP recordings, at least three studies must have computed the same COP feature in similar, quietstanding conditions. This meant that they used the same type of study and that participants were asked to maintain the same foot position and eye conditions (i.e. open, closed or blindfolded) in order to reduce interstudy inconsistency as far as possible. The algorithm to compute the pooled results was developed under Python Language Reference v3.7.2 (Python Software Foundation) to allow a sensitivity analysis regarding the experimental conditions (Quijoux et al., 2020).

\subsection{Overall quality of the evidence}

The overall quality of the evidence per outcome was evaluated by a rating system (Quijoux et al., 2019) adapted from the GRADE system (Ryan and Hill, 2016) for longitudinal follow-up studies. This assessment estimated the overall risk of bias for each variable by rating (i) the number of studies using this variable, (ii) their average risk of bias score, (iii) data heterogeneity, as measured by $\mathrm{I}^{2}$ (Higgins et al., 2003) and (iv) the cumulative sample size. To visualize possible publication biases, funnel diagrams were used; they represented the estimated effect size of each article in relation to the average standard error mean as plotted on the vertical axis. A symmetrical inverted funnel shape indicated that there was no publication bias.

\subsection{Dataset duplication}

One important factor we encountered which affected our analysis was dataset duplication. This was where certain authors appeared to have used the same data set for several different (published) studies. For example, Baloh et al. (1998a) used the same sample as Baloh et al. (1994, 1998b) used some of the same data as Baloh et al. (1995); Merlo et al. (2012) used the same data set as Maranesi et al. (2016); Topper et al. (1993), as reported by (Piirtola and Era, 2006), used data from two studies published by Maki et al. (Maki, 1993; Maki et al., 1991) while Lajoie and Gallagher (2004) used a part of the dataset from a previous article (Lajoie et al., 2002). In all of these cases, we used the most recent report for data extraction and the other studies were reviewed as sources of complementary information. For Hur et al. (2009a), we used information from Leveille et al. (2008) to define the inclusion criteria and used (Hur, 2011) for participants' demographics and (Hur et al., 2009b) as a reference for data extraction. 


\section{Results}

The original search identified more than 4000 publications as potentially relevant for addressing the question of discriminating fallers from non-faller based on quiet stance testing. After reading all of their titles and abstracts, 546 articles were subsequently screened in more detail for possible inclusion. These reviews led to a total of 50 studies being eligible for qualitative analysis but after removing reports that used duplicate datasets from other articles, a total of 44 articles ( $n=$ 7176 participants) remained for final analysis (Fig. 1) (List of included studies - Supplementary material).

\subsection{Qualitative analysis}

\subsubsection{Risk of bias assessment}

From the 26-item check list, the risk of bias evaluation revealed a moderate risk of bias, with a mean score of $15 \pm 4 / 32$ [range: 8-23]. To assess the overall methodological quality of each article, the criteria assessed with the checklist awarded one point if it was met or zero if it was not, except for two criteria. One assessing the generalizability of the results (awarding up to 2 points) and the other assessing the statistical power of the study (awarding up to 5 points). The score is therefore the sum of the points obtained. Only 18 studies reported the number of falls and the COP features computed for each group of participants. Otherwise, studies reported recording conditions well (n $=38)$ and used appropriate statistics $(\mathrm{n}=34)$. The studies included in the quantitative analysis had a mean score of $16 \pm 3 / 32$ and the excluded studies $13 \pm 3 / 32$.

\subsubsection{Demographics data}

From the total pooled population of 7176 older participants, 4842 were older non-fallers (NFs), 1554 were occasional fallers (OFs; defined as having fallen at least once) and 640 were frequent fallers (FFs; defined as having had two or more falls). There was also a group of 140 people who were described as unrecorded fallers (UFs), since records about how many times they fell were unavailable. Some studies grouped FFs (who had $\geq 2$ falls during follow-up) with OFs (who had one recorded fall during the same period).

Only 28 of 44 studies reported sufficient information regarding participants' characteristics and inclusion criteria, the most common issue was the pooling of demographic data for fallers and non-fallers. Of the data available, the mean age of the NFs was $76 \pm 5$ years. For the fallers group, the average age was $77 \pm 6$ years (OFs) and $77 \pm 4$ (FFs), although these data came from the 31 studies who reported the mean ages of each group separately. The studies lacked data regarding weight, height or body mass index (BMI). Ten studies reported data regarding cognitive evaluation (Mini Mental State Evaluation [MMSE]), although this information was used as an inclusion criterion. For example, Hur et al. (2009a); Laughton et al. (2003) and Park et al. (2014) used a cognitive test and participants were excluded below a certain score $(24 / 30,24 / 30$ and $18 / 30$, respectively) but none reported clear values of the cognitive evaluation.

Among the 7176 participants, most (80 \%) were not institutionalized. Overall, 3495 (49 \%) were community-dwelling people and 2234 (31\%) lived independently. Only 349 (5\%) lived in a nursing home and $338(10 \%)$ were patients seen in medical settings. Therefore, although the average age of the population was over 75 years, for more than two thirds of the subjects there were no indications in the data of any existing pathology that would have affected their balance and therefore it could not be assumed that these people were fragile. Demographic information was not clear for $10 \%$ of the pooled population and so could not be used.

\subsubsection{Fall evaluation}

One issue that was identified from the studies examined was that the definition of 'a fall' differed between authors. This was an important point, since it influenced the number of falls that each research group recorded and the final classification of a patient as either a faller or a non-faller. In total, 23 studies used a referenced definition for classification of a fall; most chose either the definition from the Kellogg International Work Group (Kellogg International Work Group, 1987) and or from Tinetti et al. (Tinetti et al., 1988). In terms of classification, falls were often not associated with their consequences (e.g. a sustained injury or hospitalization). Among the 44 studies reviewed, the authors of the 26 retrospective papers based their identification of fallers on a history of falls following a physical interview and fall questionnaires or $(n=1)$ incident reports. For prospective studies $(n=15)$, the usual way to follow participants was to ask them to send back a calendar recording falls or postcards with $(n=10)$ or without $(n=2)$ phoning the person for complementary information. Thirteen (54\%) retrospective studies defined the faller group based on the presence of $\geq 1$ falls in the previous 12 months before assessment. Similarly, six (40\%) prospective studies classified older people as fallers when they had a fall in the 12 months of follow-up. The period of interest was rarely longer than 12 months because of the difficulty following older participants.

\subsubsection{Measurement conditions}

Information regarding COP recording protocols was usually adequately detailed $(n=38 / 44)$. We noted some variability in the recording methodologies regarding the quiet-standing position (Fig. 2). Protocols included recording without a dual task (84 \%), with one with eye open using a blindfold or with eyes closed (77\%). When information was available about recording conditions such as gaze direction ( $43 \%$ ) or posture (43\%), the most frequently used assessment technique was to ask the participant to look at a target that had been placed at eye level $<4 \mathrm{~m}$ away $(\mathrm{n}=12)$, to stand as still as possible ( $\mathrm{n}$ $=15)$ with arms at the sides $(n=21)$, barefoot $(n=23 / 44 ; 3$ studies accepted flat shoes and 18 provided no information) and with feet placed in a comfortable position $(n=21)$ or in a narrow position with toes and heels touching $(\mathrm{n}=10)$. In six studies, a condition using a foam pad was also set in addition to recording on the firm surface of the COP measurement tool. Most of the recording durations were $<35 \mathrm{~s}$ (n $=34)$. About half of the protocols $(n=21)$ specified several recordings [range: 2-10] to average the results or use only one of them.

\subsubsection{Features computed}

The diversity of the parameters derived from the COP trajectory can be confusing for practitioners. We classified the extracted features following Prieto et al. (1996) to summarize the use of the most common variables (List of center of pressure features and their definition Supplementary material). The most common feature was 'COP mean velocity' $(n=29)$ in either the anteroposterior (AP) and mediolateral (ML) direction or in the radial direction (a combination of the two planes). 'Surface', defined as the area containing the COP trajectory (Rasku et al., 2012), was also widely used and 17 studies used it for their classification of fallers and non-fallers. Few studies shared the same recording conditions and similar COP features (Fig. 3). Surface was expressed in multiple ways, depending on the authors. Given this lack of information on calculation methods, different statokinesiogram surface values were grouped together without distinction being made between either the percentage of points included or the shape of the surface (which was generally circular or elliptical). As a result of these assumptions, therefore, our quantitative analysis excluded variables from several complex features which were included in only a few studies, such as time-frequency analysis of the COP time series as they could not be included in the meta-analysis.

The included studies mainly concluded on the inability of these features to find differences between fallers and non-fallers (Aufauvre et al., 2005; Maranesi et al., 2016; Muir et al., 2013), but some inconsistency was seen across studies (Bauer et al., 2010, 2016; Hur et al., 2009b; Lajoie et al., 2002; Lajoie and Gallagher, 2004). On the other 
(a)

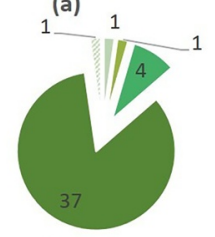

$\llbracket$ Arithmetic

घ Auditory \& verbal

n Counting

- No

(b)

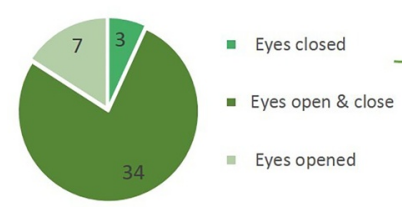

(c)

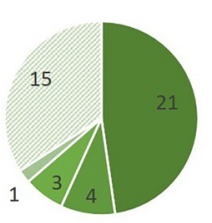

- at their sides

- behind back

- clapsed together

crossed over chest

No info (d)

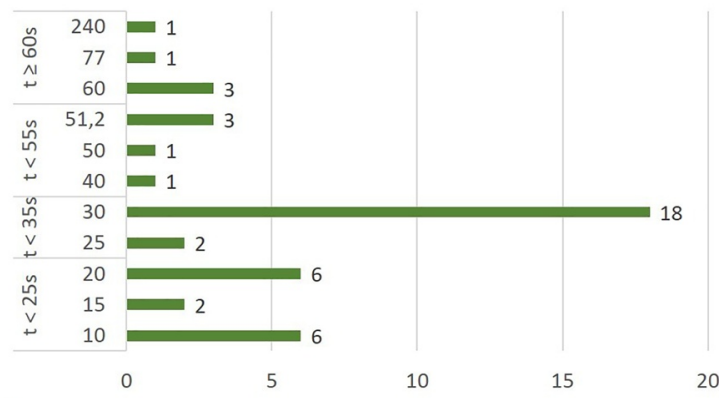

(e)

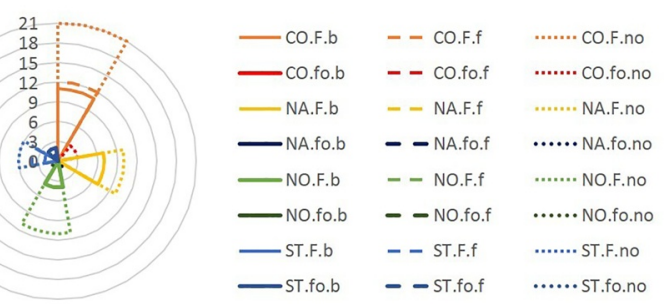

- Co: comfortable/ Na: narrow/ NO: no information/ ST: standardized - F: firm/ fo: foam

...... b: barefoot/ f: flat shoes accepted/ no: no information

Fig. 2. Conditions of recordings.

(a) Dual-task

(b) Eyes open or closed

(c) Hand position

(d) Duration of recording

(e) Feet position and surface

- Co: comfortable/ Na: narrow/ NO: no information/ ST: standardized

- -F: firm/ fo: foam

b: barefoot/ f: flat shoes accepted/ no: no information

Recording conditions varied in order to increase the difficulty of the quiet stance tasks. These included the addition of (a) a dual task, (b) visual sensory deprivation or foot position and the addition of a foam cushion (e). The most frequently reported foot position was a comfortable position (as defined either by the researchers or the test subject). A standardized position orientates the feet and defines the distance between the heels and metatarsals. Arms are generally positioned in a relaxed manner next to the body but often too little information was given (c). Recording duration also varied; there were more short recordings of less than $35 \mathrm{~s}$ (d).

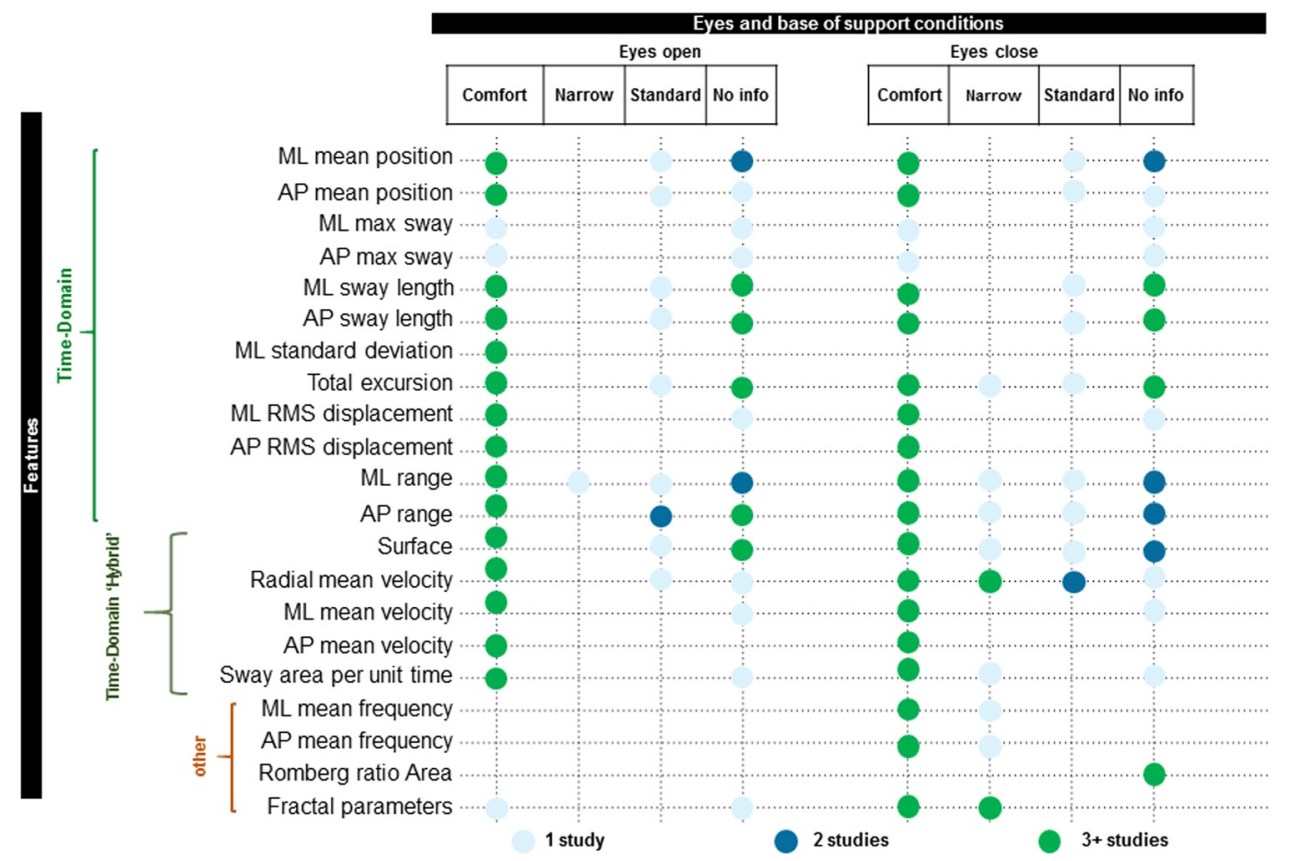

Fig. 3. Number of studies using COP features per condition.

ML: mediolateral; AP: anteroposterior; RMS: root mean square

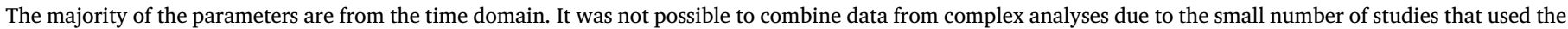
same recording conditions. 
Table 1

Significant features for each condition with $\mathrm{n} \geq 3$ number of studies. Overall evidence ranges from very low and low to moderate and high.

\begin{tabular}{|c|c|c|c|c|c|c|c|c|}
\hline & & & $\begin{array}{l}\text { Risk of bias } \\
\text { score } \\
\text { (mean of the } \\
\text { 32-score) }\end{array}$ & $\begin{array}{c}\text { Number } \\
\text { of studies } \\
\text { (n) }\end{array}$ & $\begin{array}{c}\text { Heterogeneity } \\
\left(I^{2}\right)\end{array}$ & $\begin{array}{l}\text { Cumulative } \\
\text { sample size }\end{array}$ & Quality & \\
\hline & & & $>22$ & $>10$ & $<\mathbf{3 0} \%$ & $>400$ & High & \\
\hline & & & $16-22$ & 3-10 & $30-75 \%$ & $200-400$ & Moderate & \\
\hline Condition & Feature & p-value & $<16$ & $0-3$ & $>75 \%$ & $<200$ & Low & $\begin{array}{r}\text { Overall } \\
\text { evidence }\end{array}$ \\
\hline Retrospective & AP sway length & 0.039 & 13.33 & 6 & $45 \%$ & 420 & 4 & Low \\
\hline & ML range & 0.049 & 13.80 & 13 & $88 \%$ & 894 & 4 & Low \\
\hline & AP mean velocity & 0.027 & 16.67 & 6 & $27 \%$ & 617 & 6 & Moderate \\
\hline & $\begin{array}{l}\text { Radial mean } \\
\text { velocity }\end{array}$ & 0.003 & 15.50 & 16 & $88 \%$ & 1531 & 4 & Low \\
\hline & $\begin{array}{l}\text { Sway area per unit } \\
\text { time }\end{array}$ & $<0.001$ & 16.40 & 5 & $0 \%$ & 444 & 6 & Moderate \\
\hline $\begin{array}{l}\text { Retrospective } x \\
\text { EC } x\end{array}$ & $\begin{array}{l}\text { Sway area per unit } \\
\text { time }\end{array}$ & 0.012 & 17.00 & 3 & $0 \%$ & 264 & 5 & Moderate \\
\hline Coritivitavie & $\begin{array}{l}\text { Radial mean } \\
\text { velocity }\end{array}$ & 0.028 & 16.50 & 4 & $96 \%$ & 412 & 4 & Low \\
\hline Prospective & AP mean position & 0.006 & 17.00 & 4 & $21 \%$ & 540 & 6 & Moderate \\
\hline & ML sway length & 0.011 & 18.00 & 8 & $66 \%$ & 1732 & 5 & Moderate \\
\hline & Total excursion & 0.008 & 19.00 & 10 & $81 \%$ & 4834 & 4 & Low \\
\hline & $\begin{array}{l}\text { AP RMS } \\
\text { displacement }\end{array}$ & 0.005 & 15.50 & 4 & $46 \%$ & 392 & 3 & Low \\
\hline & AP mean velocity & 0.005 & 16.33 & 6 & $28 \%$ & 1208 & 6 & Moderate \\
\hline & $\begin{array}{l}\text { Radial mean } \\
\text { velocity }\end{array}$ & $<0.001$ & 17.29 & 7 & $64 \%$ & 970 & 5 & Moderate \\
\hline Prospective $x$ & AP mean velocity & 0.008 & 16.33 & 3 & $0 \%$ & 604 & 6 & Moderate \\
\hline Comfortable & $\begin{array}{l}\text { Radial mean } \\
\text { velocity }\end{array}$ & 0.001 & 16.33 & 3 & $40 \%$ & 436 & 5 & Moderate \\
\hline $\begin{array}{l}\text { Prospective } \mathrm{x} \\
\text { EC x } \\
\text { Comfortable }\end{array}$ & $\begin{array}{l}\text { Radial mean } \\
\text { velocity }\end{array}$ & 0.001 & 16.33 & 3 & $28 \%$ & 436 & 6 & Moderate \\
\hline $\mathrm{EO}$ & AP mean position & 0.012 & 15.80 & 5 & $9 \%$ & 490 & 5 & Moderate \\
\hline & ML sway length & 0.013 & 16.71 & 7 & $77 \%$ & 1054 & 4 & Low \\
\hline & Total excursion & 0.002 & 17.11 & 9 & $80 \%$ & 2678 & 4 & Low \\
\hline & $\begin{array}{l}\text { AP RMS } \\
\text { displacement }\end{array}$ & 0.006 & 15.25 & 4 & $35 \%$ & 415 & 4 & Low \\
\hline & AP mean velocity & 0.002 & 16.50 & 6 & $37 \%$ & 907 & 5 & Moderate \\
\hline & $\begin{array}{l}\text { Radial mean } \\
\text { velocity }\end{array}$ & $<0.001$ & 15.60 & 9 & $49 \%$ & 1131 & 4 & Low \\
\hline & $\begin{array}{l}\text { ML Standard } \\
\text { Deviation }\end{array}$ & $<0.001$ & 15.67 & 3 & $0 \%$ & 411 & 5 & Moderate \\
\hline & $\begin{array}{l}\text { Sway area per unit } \\
\text { time }\end{array}$ & 0.027 & 16.50 & 4 & $52 \%$ & 788 & 5 & Moderate \\
\hline $\mathrm{EC}$ & ML range & 0.040 & 15.67 & 9 & $92 \%$ & 711 & 3 & Low \\
\hline & AP mean velocity & 0.050 & 16.50 & 6 & $5 \%$ & 918 & 6 & Moderate \\
\hline & $\begin{array}{l}\text { Radial mean } \\
\text { velocity }\end{array}$ & 0.003 & 16.39 & 13 & $91 \%$ & 1370 & 5 & Moderate \\
\hline
\end{tabular}

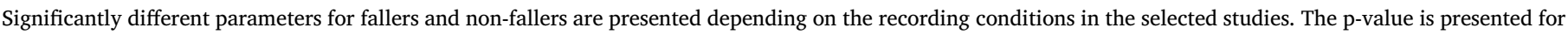

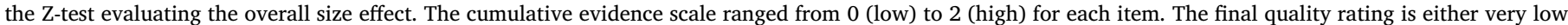
$(<2)$, low (2-4), moderate (5-6) or high $(>6)$.

hand, several studies found that performance of a Stabilogram Diffusion Analysis (SDA), a stochastic method based on the auto-correlation of the COP trajectory, was significantly predictive of falling. The SDA could reveal two regimes characterized by their postural behavior, defined as an open-loop and a close-loop reaction on a short and a long- term respectively (Soangra and Lockhart, 2012). Elderly fallers demonstrated significantly greater short-term coefficients (Kurz et al., 2013; Melzer et al., 2010; Muir et al., 2013), without a specific direction being identified. Other author reported the advantage of SDA to identify fallers from non-fallers (Hur et al., 2009b; Tuunainen et al., 


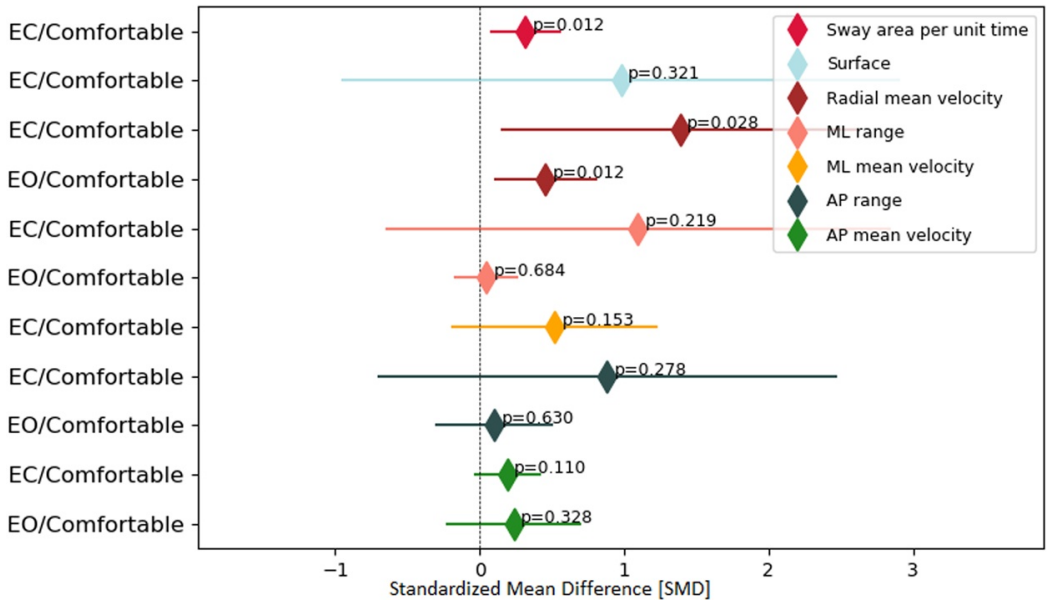

Fig. 4. Forest plot of COP features for retrospective history of fall. The overall effect size (with $95 \%$ confidence intervals) is represented by the horizontal bar. The p-value represents the Z-test results for the approximate mean differences.

(a) AP mean velocity for porpsective follow-up and comfortable feet position (EC in red, EO in blue); (b) Radial mean velocity for prospective follow-up and comfortable feet position (EC in red, EO in blue); (c) Radial mean velocity for retrospective history of falls and comfortable feet position (EC in red and EO in blue); (d) Sway area per unit time for retrospective history of falls and comfortable feet position (EC in red).
2014), with various related features.

In contrast, three other studies (Borg and Laxåback, 2010; Laughton et al., 2003; Qiu and Xiong, 2015) did not find that SDA results allowed reliable differentiation between older non-fallers and fallers. It is of note, however, that these 3 studies also showed a higher risk of bias with scores of 11/32, 11/32 and 12/32 (respectively) whereas those studies that reported SDA to be an effective tool had scores from 13 to 23.

This finding may indicate an ability to distinguish fallers from nonfallers with parameters extracted from complex analysis. Unfortunately, we could not combine the results of these studies because of the heterogeneity of the recording conditions and the different directions (AP, ML and radial) in which the features were calculated.

\subsubsection{Predictive models}

Several authors attempted to use predictive models based on COP features to classify participants as fallers and non-fallers or even to predict the number of falls for a participant. Taken alone, or combined with clinical variables, COP features were reported to have achieved an overall classification accuracy, based on the area under the receiver operating characteristic curve, ranging from 0.43 (Caterino et al., 2009) to 0.77 (Bargiotas et al., 2018). For sensitivity, participants were correctly predicted as fallers, with an accuracy that ranged from $29 \%$ to $82 \%$. For specificity, participants were correctly predicted as nonfallers, with an accuracy that ranged from $43 \%$ to $92 \%$. As compared with the standard test with feet in a comfortable position, tests where participants were asked to adopt a narrow stance gave little or no additional information regarding fall risk prediction (Caterino et al., 2009; Mertes et al., 2015). Moreover, this narrow stance was found to be too difficult for some older individuals (Bigelow and Berme, 2011).

The added value of a blindfolded test was suggested in several studies (Audiffren et al., 2016; Brauer et al., 2000; Caterino et al., 2009; Deschamps et al., 2016; Howcroft et al., 2017; Maki et al., 1994; Panzer et al., 2011). Various authors also reported that ML features data significantly accurately predicted fall status (Audiffren et al., 2016; Bauer et al., 2016) and that their accuracy was superior to results from AP data (Bergland et al., 2003; Bigelow and Berme, 2011; Maki et al., 1994; Stel et al., 2003; Swanenburg et al., 2010). Several authors, however, failed to find predictive ability with COP features alone (Brauer et al., 2000; Buatois et al., 2006; Caterino et al., 2009; Lajoie and Gallagher, 2004; Pajala et al., 2008) and others reported that the predictive value of COP data was improved when nutritional status or anthropomorphic characteristics, for example, were added to clinical data (Bigelow and Berme, 2011; Deschamps et al., 2016). Several studies used results from established clinical tests such as the Berg Balance Scale (Bauer et al., 2016; Brauer et al., 2000), the Tinetti POMA (Bauer et al., 2016; Panzer et al., 2011) and TUG test (Bauer et al., 2016;
Bergland et al., 2003; Buatois et al., 2006; Caterino et al., 2009), clinical tests failed to show predictive quality as compared with COP data. In multivariate models, the quantification of anterior maximal lean excursion, such as in the Functional Reach test, could slightly improve the prediction (Bergland et al., 2003; Panzer et al., 2011).

\subsection{Meta-analysis}

\subsubsection{Quantitative analysis}

Twenty-nine studies were included in the quantitative analysis. Using retrospective classification of patients' fall status (based on their fall history) five features differed significantly between non-fallers and fallers in all studies (Table 1$)$ : AP sway length $(\mathrm{n}=6 ; \mathrm{p}=0.039 ; \mathrm{Z}=$ $\left.2.07 ; \mathrm{I}^{2}=45 \%\right)$, AP mean velocity $\left(\mathrm{n}=6 ; \mathrm{p}=0.027 ; \mathrm{Z}=2.21 ; \mathrm{I}^{2}=\right.$ $27 \%)$, ML range $\left(\mathrm{n}=13 ; \mathrm{p}=0.049 ; \mathrm{Z}=1.96 ; \mathrm{I}^{2}=88 \%\right)$, radial mean velocity $\left(\mathrm{n}=16 ; \mathrm{p}=0.003 ; \mathrm{Z}=2.92 ; \mathrm{I}^{2}=88 \%\right)$ and sway area per unit time $\left(n=5 ; p<0.001 ; Z=4.09 ; I^{2}=0 \%\right)$, which was defined as the area enclosing the COP trajectory per second.

From prospective classification of fall status, six features significantly differed between (future) non-fallers and fallers in prospective studies: AP mean position $\left(\mathrm{n}=4 ; \mathrm{p}=0.006 ; \mathrm{Z}=2.74 ; \mathrm{I}^{2}=\right.$ $21 \%$ ), AP RMS displacement ( $\mathrm{n}=4 ; \mathrm{p}=0.005 ; \mathrm{Z}=2.83 ; \mathrm{I}^{2}=46 \%$ ), AP mean velocity $\left(n=6 ; p=0.005 ; Z=2.78 ; I^{2}=28 \%\right)$, ML sway length ( $\mathrm{n}=8 ; \mathrm{p}=0.011 ; \mathrm{Z}=2.55 ; \mathrm{I}^{2}=66 \%$ ), radial mean velocity ( $\left.\mathrm{n}=7 ; \mathrm{p}<0.001 ; \mathrm{Z}=3.59 ; \mathrm{I}^{2}=64 \%\right)$ and total excursion $(\mathrm{n}=10 ; \mathrm{p}$ $=0.008 ; \mathrm{Z}=2.64 ; \mathrm{I}^{2}=81 \%$ ). Because the conditions of recording could change the ability to discriminate between fallers and non-fallers, both foot position and eye condition (open/closed) were taken into account in the sensitivity analysis.

\subsubsection{Sensitivity analysis}

The visual information could play a major role in the postural strategy to maintain balance, the data were divided into eyes open (EO) and eyes closed (EC) conditions during the recording. Also, foot position may affect the measurement of the COP trajectory. Therefore, we used a sensitivity analysis to select studies classifying fallers with the same recording settings. Both sway area per unit time and radial mean velocity data also allowed discrimination of fallers from non-fallers in the interaction: Retrospective $\mathrm{x}$ EC x Comfortable $(\mathrm{n}=3 ; \mathrm{p}=0.012 ; \mathrm{Z}$ $=2.50 ; \mathrm{I}^{2}=0 \%$ and $\mathrm{n}=4 ; \mathrm{p}=0.028 ; \mathrm{Z}=2.503 ; \mathrm{I}^{2}=96 \%$ ) (Fig. 4). In prospective studies (Fig. 5), the radial mean velocity was significantly different for both visual conditions (Prospective $\mathrm{x}$ EO $\mathrm{x}$ Comfortable: $\mathrm{n}=3 ; \mathrm{p}<0.001 ; \mathrm{Z}=3.366 ; \mathrm{I}^{2}=40 \%$ and: Prospective x EC x Comfortable: $\mathrm{n}=3 ; \mathrm{p}=0.007 ; \mathrm{Z}=2.689 ; \mathrm{I}^{2}=28 \%$ ). However, AP mean velocity was significantly different in only the EO condition (Prospective $\mathrm{x}$ EO $\mathrm{x}$ Comfortable: $\mathrm{n}=3$; $\mathrm{p}=0.008 ; \mathrm{Z}=$ $\left.2.655 ; \mathrm{I}^{2}=0 \%\right)$. For the features significantly discriminating fallers and 


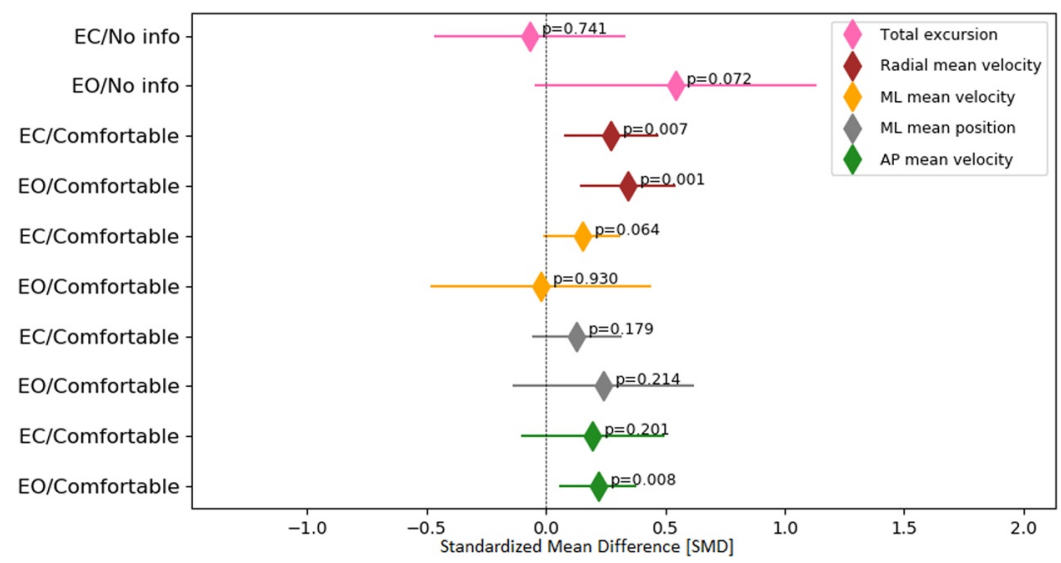

Fig. 5. Forest plot of COP features for prospective fall recording.

The overall effect size (with $95 \%$ confidence intervals) is represented by the horizontal bar. The p-value represents the Z-test results for the approximate mean differences.

non-fallers, the study protocols vary on whether or not shoes are worn during recording. Thus, for the sway area per unit time in the interaction Retrospective $\mathrm{x}$ EC $\mathrm{x}$ Comfortable, the three articles used the three possible footwear conditions (i.e., barefoot, with shoes and without information). There is slightly less variability in the wearing of shoes for the other parameters because the measurements were taken with participants barefoot or the articles did not provide information on this topic. This finding does not seem to be related to the heterogeneity measured because the sway area per unit time had a zero heterogeneity value, whereas other parameters were more heterogeneous, despite the proximity of the protocols concerning this parameter.

Based on the averaged risk of bias score, the number of studies available that examined each parameter, the heterogeneity between studies and the cumulative sample sizes for any given variable, the overall reliability of the parameters in the differentiation of fallers from non-fallers ranged from low to moderate (Table 1). The heterogeneity of the studies is the main cause of the decrease in reliability, thus reducing the possibility of generalizing the results.

Graphical examination of the funnel plots for the studies (Fig. 6) did not reveal publication biases. Unfortunately, this was probably due to the limited number of studies available for each outcome rather than a definite absence of bias. Due to the difficulty of interpreting these graphs, therefore, it was not possible to exclude the possibility of publication bias. This is something that presented a major limitation to the generalization of results across the studies reviewed.

\section{Discussion}

\subsection{Summary of overall evidence}

To our knowledge, this systematic review is the first to examine the classification quality of stabilogram features by performing meta- and sensitivity analyses over different COP recording conditions in order to differentiate fallers from non-fallers in an older population. Although several studies had previously agreed that older fallers exhibit higher COP displacements than older non-fallers during a quiet standing task, the best postural markers to distinguish these two groups remained undefined. In order to answer to that question, this review identified several studies out of a corpus of approximately 4000 studies that had been published in both peer-reviewed journals and gray literature (Conn et al., 2003).

Our results highlighted the ability of a simple quiet-standing task (with eyes open or closed in a comfortable position) to distinguish fallers from non-fallers in an elderly population. The interaction of study type, visual and foot position conditions, identified velocity in both anteroposterior and radial directions and the sway area per unit time as the best features for discriminating between fallers and nonfallers.

Despite the significant capability of some parameters to differentiate between fallers and non-fallers, it is necessary to emphasize that the generalization of these results may be limited by the overall quality of the evidence which ranged from low to moderate. As mentioned, the heterogeneity of the studies led to a low reliability of the ability to differentiate elderly people with a history of falls from the radial mean velocity parameter. The use of these radial mean velocity data therefore seems more relevant for longitudinal follow-ups since future retrospective studies could potentially contradict its efficacy. The other parameters ('AP mean velocity' and 'sway area per unit time'), which were considered moderately reliable, require more testing in larger cohorts in future studies. Nevertheless, it seems reasonable to use 'AP mean velocity' and 'sway area per unit time' in predictive models since they were moderately reliable.

At the time of writing, the diagnosis of the risk of falling remains a subjective clinical approach. Eventually, uni- or multivariate predictive models based on velocity parameters could provide a source of additional information on the effectiveness of therapy in reducing the risk of falling. This development is made possible by the reduced cost of the force platforms, as well as their increased portability and connectivity functions which means that they could be coupled with automatic data processing enabled by machine learning algorithms (Zhavoronkov et al., 2019).

The frequency and stochastic analysis of quiet stance posturography data may be relevant to detect persons at risk of falling (Gilfriche et al., 2018; Kouzaki and Masani, 2012; Schumann et al., 1995; Suzuki et al., 2017) or possible neurological impairments (Salsabili et al., 2013). Despite the known benefits of such analyses, however, and the recognition of the additional clinical value they bring (Baratto et al., 2002; Chiari et al., 2000; König Ignasiak et al., 2017; Rasku et al., 2012; Tallon et al., 2013) at present they remain time-consuming and difficult to perform, which explains their scattered presence in the literature. In addition, apart from sway density (Audiffren et al., 2016; Maranesi et al., 2016), other calculated COP parameters are summary measures and do not reflect the dynamic of balance during the quiet stance test. Given the high AUC obtained by Bargiotas et al. (2018) with traditional features applied on local windows over the COP signal, it seems reasonable for future research to continue investigating local dynamic analysis.

Our results have emphasized the discriminative properties of the COP data extracted from the sagittal plane. We also found that results from analysis of ML data were more heterogenous than AP results under all test conditions. These findings contrast with systematic reviews by Piirtola and Era (2006) and Watt et al. (2018) where ML data were 
a)

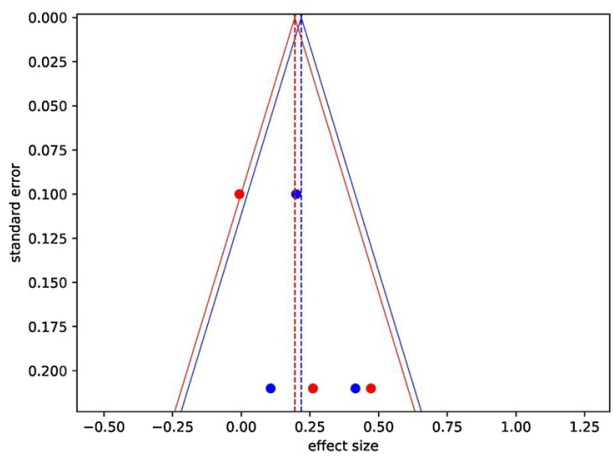

c)

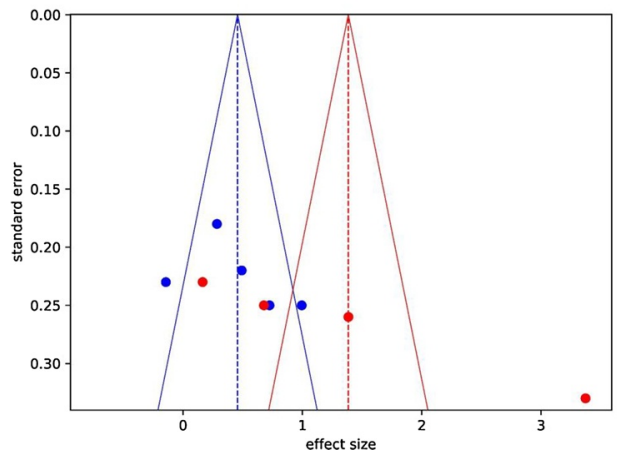

b)

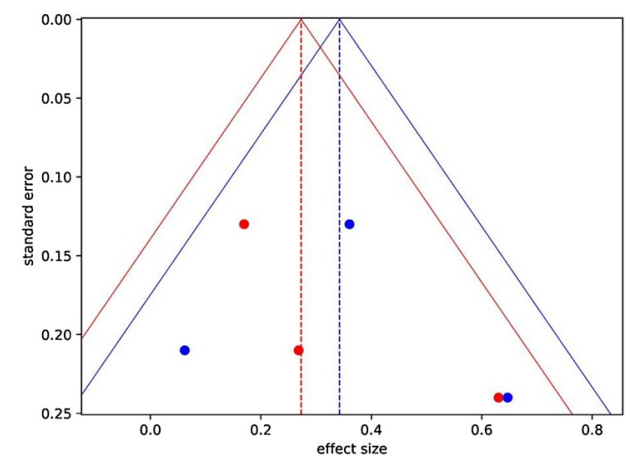

d)

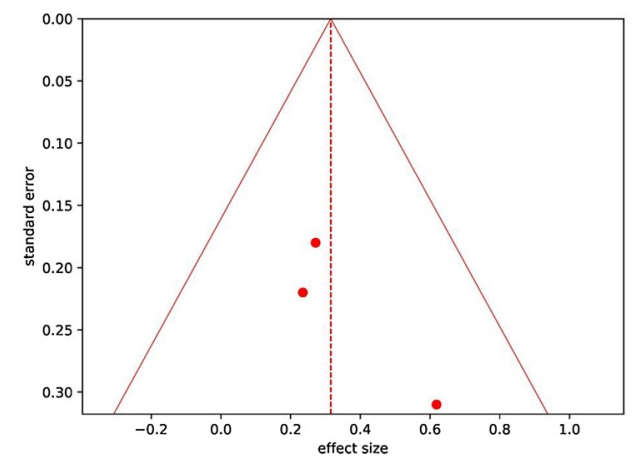

Fig. 6. Funnel plots of COP features significantly different between non-fallers and fallers in various interactions of conditions.

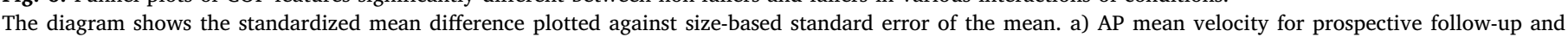

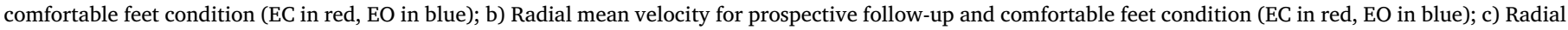

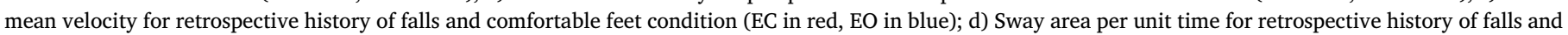
comfortable feet position (EC in red).

found to be more discriminatory than AP features. Such contradictory conclusions, we believe, can be explained by the fact that we stratified the data into three conditions (namely by study type, whether participants had their eyes open or closed and also the position of their feet). This stratification led to the exclusion of ML data from the set of differentiating COP displacement characteristics and this exclusion highlighted the importance of explicitly controlling test conditions which are currently inconsistently applied between studies (for factors such as what participants are asked to do with their eyes during testing or how and where they should place their feet). In future studies, this standardization would allow stabilographic data to be pooled across studies; this would increase the power of the findings and so enable recommendations to be more reliably drawn between studies.

\subsection{Variability in the procedure to record COP displacements}

It seemed reasonable to pool data across the studies due to reliability of the parameters across recording protocols (Bauer et al., 2008; Schubert et al., 2012), especially for the COP velocity (Lafond et al., 2004; Li et al., 2016; Lin et al., 2008; Lovecchio et al., 2016; Moghadam et al., 2011; Schmid et al., 2002; Swanenburg et al., 2008). The heterogeneity measured in this meta-analysis could have been explained in part by the variation in the quiet-standing recordings among studies. Recommendations proposed to reduce variability of the COP features include increasing the duration of the recordings (Schmid et al., 2002). However longer durations to increase inter-subject reliability, seem incompatible with physical abilities of older participants. Also, repetitive trials could improve the reliability between participants, but only half of the included studies used more than one recording. Few studies (Hewson et al., 2010; Hur et al., 2009b; Kurz et al., 2013; Laughton et al., 2003; Melzer et al., 2010; Seidler and Martin, 1997) recorded the balance of the participants five or more times, as recommended to improve the robustness of the data (Golriz et al., 2012; Santos et al., 2008). The exception is Hewson et al. (2010), whose population was community-dwelling people living independently, with a mean age below 80 years old, which argues for some limits regarding the feasibility of repetitive measures for institutionalized older people. It should therefore be noted that the simplicity of the test will serve the most fragile people and should still allow the distinction between those most at risk, without the need to make the test more complex by asking to stay on one foot for example.

In nursing homes, we believe that access to a simple and reliable measurement of balance would be particularly useful. Although most of the selected studies focused on independent seniors, the issue of falling in people over 80 years of age is of greater concern. Correlated to age, the number of falls per person goes hand in hand with the loss of autonomy, which is itself responsible for new falls (Institut national de la santé et de la recherche médicale (Inserm, 2015). The absence of clinical test results in predictive models highlights the lack of sensitivity of the tools currently used in daily practice to monitor the physical capacities of institutionalized people. It therefore seems necessary to continue the trials in nursing homes to collect more data and determine parameters that are more specific to this population.

\subsection{Co-contractions and COP}

The differentiation quality of AP mean velocity could be explained by the fact that participant needed to maintain stiffness because of agonist-antagonist muscle co-contraction around the ankle (Baudry and Duchateau, 2012, 2012; Goble et al., 2009; Papegaaij et al., 2014; Vette et al., 2017). Co-contractions have been shown to produce faster AP COP movements (Benjuya et al., 2004; Carpenter et al., 2001; Ho and Bendrups, 2002; Nelson-Wong et al., 2012). Because radial mean velocity is calculated from a combination of speed in both directions, cocontractions affecting AP velocity would also affect the radial velocity. Therefore, radial mean velocity of the COP (in $\mathrm{mm} / \mathrm{s}$ ) and the sway area per unit time (in $\mathrm{mm}^{2} / \mathrm{s}$ ) may be correlated, but the impact of co-contractions on the latter is less clear. Co-contractions of leg muscles in the 
older adult may also lead to inappropriate motor responses (Delignières et al., 2011; Jeka et al., 2004; Le Mouel and Brette, 2017; Masani, 2003), particularly in relation to the inhibitory mechanisms involved in the process of motor response selection (Duque et al., 2014).

\subsection{Limitations}

The first limitation in our review is that three papers which appeared to be suitable for inclusion had to be rejected as no one could read them (they were written in Portuguese, Japanese and Arabic). We attempted to circumvent this problem by searching the gray literature and other information that was related to these papers, but we could not find anything.

The second limitation of this systematic review is the absence of analysis by number of falls. Older adults who fell once during the follow-up period were not always separated from those who fell frequently (i.e. twice or more) or from those who did not fall at all.

Thirdly, little information was available on the conditions under which the falls occurred; as a result, we were unable to distinguish the number of incidents per participant or the injuries associated with these falls. It would be preferable in future studies to add information on fall injuries as this would allow predictive models to be stratified according to the severity of the fall consequences (James et al., 2018). Because it is easier to distinguish FFs from NFs or from OFs, we can assume that simple predictive models will be more effective in discriminating very high-risk individuals from robust older people.

It also seems necessary to include more institutionalized older people because our review highlighted the lack of studies investigating the COP of dependent people. This could have an impact on the outcomes presented here (Rubenstein et al., 1994). Indeed, with a mean age of 77 years in our study, these results could not be generalized to all frail older people without more data collected from extended care settings. Because of their social (Bloch et al., 2010), cognitive (Kamińska et al., 2015; McMichael et al., 2008; Montero-Odasso et al., 2012) and physical dependence (Deandrea et al., 2013), older adults in residential care are more likely to fall but also more difficult to follow in a longitudinal design. Also, although cognitive disorders can affect both postural strategy and the incurred risk to put individuals in danger, these were not reported in most of the studies. Hence, we were not able to perform a sensitivity analysis on cognitive status.

Dual cognitive tasks or standing on a surface such as foam are used to increase the challenge of balance tests (Al-Yahya et al., 2011; Bergamin et al., 2014; Lacour et al., 2008; Woollacott and ShumwayCook, 2002). However, an analysis of the interaction: Faller status $x$ Surface $\mathrm{x}$ Task was not found to be significant (Shumway-Cook et al., 1997). In the present study, unfortunately, we could not investigate this further since we could not pool data from studies using cognitive dualtask or foam owing to the diversity of the COP variables used and the variety of recording conditions.

Another issue with the reporting of or defined conditions for testing was that many articles did not provide information on whether participants were wearing shoes during recording. Footwear could have a negative impact on the postural balance of older people by reducing the sensory inferences of the skin on the sole of the foot (Hijmans et al., 2007) although heel size has previously been shown to not affect the COP displacement in older adults (Lindemann et al., 2003). In this review, unfortunately, we were unable to sub-stratify the sensitivity analysis because of the small number of tests that stated they allowed footwear.

Finally, other variables such as personal characteristics (BMI, a history of falls or even nutrition) could be relevant to improve the ability to discriminate fallers from non-fallers.

\section{Conclusion}

Despite a discrepancy between the included studies regarding the condition of recording, this review suggests that sway area per unit time can differentiate fallers from non-fallers. In addition, prospective studies have shown that the mean velocity in the AP direction and in the radial direction were significantly different between fallers and nonfallers. ML features were less consistent and discriminative than AP features in the present meta-analysis. There is no doubt that current advances in data processing will make it possible to use COP trajectory analysis in routine consultations. The identification of parameters for classifying and predicting people at risk is therefore necessary to create effective tools for longitudinal monitoring of the most vulnerable elderly people. In the future, these markers can then be used to objectify the improvement of balancing capacities in the context of rehabilitation and promote the personalization of care (Rajagopalan et al., 2017). Given the increasing institutionalization of older people in many countries, in the absence of relevant clinical tests, connected technologies will provide support to health professionals for the follow-up of vulnerable people (Siren et al., 2019).

\section{Systematic review registration}

This review was registered with PROSPERO (International Prospective Register of Systematic Reviews) on June 19, 2018 (Registration: CRD42018098671). Both the search strategy and study protocol are available at https://www.crd.york.ac.uk/prospero/ display_record.php?RecordID $=98671$

\section{CRediT authorship contribution statement}

Flavien Quijoux: Conceptualization, Methodology, Software, Formal analysis, Investigation, Data curation, Writing - original draft, Visualization. Aliénor Vienne-Jumeau: Methodology, Software, Validation, Formal analysis, Investigation, Data curation, Writing original draft, Writing - review \& editing, Visualization. François Bertin-Hugault: Resources, Writing - review \& editing, Supervision, Project administration, Funding acquisition. Philippe Zawieja: Methodology, Resources, Writing - review \& editing, Supervision. Marie Lefèvre: Resources, Supervision. Pierre-Paul Vidal: Conceptualization, Methodology, Resources, Writing - review \& editing, Supervision, Project administration. Damien Ricard: Conceptualization, Methodology, Validation, Resources, Writing - review \& editing, Supervision, Project administration, Funding acquisition.

\section{Acknowledgements}

This study has been founded in the context of a $\mathrm{PhD}$ program in partnership with ORPEA SA. This collaboration between Cognac-G laboratory of Centre Giovanni Alfonso Borelli, Université de Paris - ENS Saclay - CNRS - SSA UMR 9010 and ORPEA group is framed in the French conventions for Industrial Training by the Research (CIFRE 2016/0437) managed by the National Association ResearchTechnology (ANRT).

\section{Appendix A. Supplementary data}

Supplementary material related to this article can be found, in the online version, at doi:https://doi.org/10.1016/j.arr.2020.101117.

\section{References}

Alcock, L., O’Brien, T.D., Vanicek, N., 2018. Association between somatosensory, visual and vestibular contributions to postural control, reactive balance capacity and healthy ageing in older women. Health Care Women Int. 1-15. https://doi.org/10. 1080/07399332.2018.1499106.

Álvarez Barbosa, F., del Pozo-Cruz, B., del Pozo-Cruz, J., Alfonso-Rosa, R.M., Sañudo Corrales, B., Rogers, M.E., 2016. Factors associated with the risk of falls of nursing home residents aged 80 or older. Rehabil. Nurs. 41, 16-25. https://doi.org/10.1002/ 
rnj.229.

Al-Yahya, E., Dawes, H., Smith, L., Dennis, A., Howells, K., Cockburn, J., 2011. Cognitive motor interference while walking: a systematic review and meta-analysis. Neurosci. Biobehav. Rev. 35, 715-728. https://doi.org/10.1016/j.neubiorev.2010.08.008.

Arfken, C.L., Lach, H.W., Birge, S.J., Miller, J.P., 1994. The prevalence and correlates of fear of falling in elderly persons living in the community. Am. J. Public Health 84, 565-570. https://doi.org/10.2105/AJPH.84.4.565.

Audiffren, J., Bargiotas, I., Vayatis, N., Vidal, P.-P., Ricard, D., 2016. A non linear scoring approach for evaluating balance: classification of elderly as fallers and non-fallers. PLoS One 11, e0167456. https://doi.org/10.1371/journal.pone.0167456.

Aufauvre, V., Kemoun, G., Carette, P., Bergeal, E., 2005. Évaluation posturale à domicile chez la personne âgée : comparaison chuteurs-non chuteurs. Annales de Réadaptation et de Médecine Physique 48, 165-171. https://doi.org/10.1016/j. annrmp.2004.12.003

Balasubramanian, C.K., 2015. The community balance and mobility scale alleviates the ceiling effects observed in the currently used gait and balance assessments for the community-dwelling older adults. J. Geriatr. Phys. Ther. 38, 78-89. https://doi.org/ 10.1519/JPT.0000000000000024.

Baloh, R.W., Fife, T.D., Zwerling, L., Socotch, T., Jacobson, K., Bell, T., Beykirch, K., 1994. Comparison of static and dynamic posturography in young and older normal people. J. Am. Geriatr. Soc. 42, 405-412. https://doi.org/10.1111/j.1532-5415.1994. tb07489.x.

Baloh, R.W., Spain, S., Socotch, T.M., Jacobson, K.M., Bell, T., 1995. Posturography and balance problems in older people. J. Am. Geriatr. Soc. 43, 638-644.

Baloh, Robert W., Corona, S., Jacobson, K.M., Enrietto, J.A., Bell, T., 1998a. A prospective study of posturography in normal older people. J. Am. Geriatr. Soc. 46, 438-443. https://doi.org/10.1111/j.1532-5415.1998.tb02463.x.

Baloh, R.W., Jacobson, K.M., Enrietto, J.A., Corona, S., Honrubia, V., 1998b. Balance disorders in older persons: quantification with posturography. Otolaryngol. Head. Neck Surg. 119, 89-92.

Baratto, L., Morasso, P.G., Re, C., Spada, G., 2002. A new look at posturographic analysis in the clinical context: sway-density versus other parameterization techniques. Motor Control 6 246-2.

Bargiotas, I., Audiffren, J., Vayatis, N., Vidal, P.-P., Buffat, S., Yelnik, A.P., Ricard, D., 2018. On the importance of local dynamics in statokinesigram: a multivariate approach for postural control evaluation in elderly. PLoS One 13, e0192868. https:// doi.org/10.1371/journal.pone. 0192868 .

Barry, E., Galvin, R., Keogh, C., Horgan, F., Fahey, T., 2014. Is the timed up and go test a useful predictor of risk of falls in community dwelling older adults: a systematic review and meta-analysis. BMC Geriatr. 14, 1.

Baudry, S., Duchateau, J., 2012. Age-related influence of vision and proprioception on Ia presynaptic inhibition in soleus muscle during upright stance: ageing and Ia presynaptic inhibition during balance. J. Physiol. 590, 5541-5554. https://doi.org/10 1113/jphysiol.2012.228932.

Bauer, C., Gröger, I., Rupprecht, R., Gassmann, K.G., 2008. Intrasession reliability of force platform parameters in community-dwelling older adults. Arch. Phys. Med. Rehabil. 89, 1977-1982.

Bauer, C., Gröger, I., Rupprecht, R., Meichtry, A., Tibesku, C.O., Gaßmann, K.-G., 2010. Reliability analysis of time series force plate data of community dwelling older adults. Arch. Gerontol. Geriatr. 51, e100-e105. https://doi.org/10.1016/j.archger.2010.01. 009.

Bauer, C.M., Gröger, I., Rupprecht, R., Marcar, V.L., Gaßmann, K.G., 2016. Prediction of future falls in a community dwelling older adult population using instrumented balance and gait analysis. Z. Gerontol. Geriatr. 49, 232-236. https://doi.org/10. 1007/s00391-015-0885-0.

Beauchet, O., Fantino, B., Allali, G., Muir, S.W., Montero-Odasso, M., Annweiler, C., 2011. Timed up and go test and risk of falls in older adults: a systematic review. J. Nutr. Health Aging 15, 933-938. https://doi.org/10.1007/s12603-011-0062-0.

Benjuya, N., Melzer, I., Kaplanski, J., 2004. Aging-induced shifts from a reliance on sensory input to muscle cocontraction during balanced standing. J. Gerontol. A Biol. Sci. Med. Sci. 59, M166-M171.

Bergamin, M., Gobbo, S., Zanotto, T., Sieverdes, J.C., Alberton, C.L., Zaccaria, M. Ermolao, A., 2014. Influence of age on postural sway during different dual-task conditions. Front. Aging Neurosci. 6. https://doi.org/10.3389/fnagi.2014.00271.

Bergland, A., Jarnlo, G.-B., Laake, K., 2003. Predictors of falls in the elderly by location. Aging Clin. Exp. Res. 15, 43-50. https://doi.org/10.1007/BF03324479.

Bigelow, K.E., Berme, N., 2011. Development of a protocol for improving the clinical utility of posturography as a fall-risk screening tool. J. Gerontol. A Biol. Sci. Med. Sci. 66, 228-233. https://doi.org/10.1093/gerona/glq202.

Błaszczyk, J.W., 2016. The use of force-plate posturography in the assessment of postural instability. Gait Posture 44, 1-6. https://doi.org/10.1016/j.gaitpost.2015.10.014.

Bloch, F., Thibaud, M., Dugué, B., Brèque, C., Rigaud, As., Kemoun, G., 2010. Episodes of falling among elderly people: a systematic review and meta-analysis of social and demographic pre-disposing characteristics. Clinics 65, 895-903. https://doi.org/10 1590/S1807-59322010000900013.

Bock, O., Schneider, S., 2002. Sensorimotor adaptation in young and elderly humans. Neurosci. Biobehav. Rev. 26, 761-767. https://doi.org/10.1016/S0149-7634(02) 00063-5.

Borel, L., Alescio-Lautier, B., 2014. Posture and cognition in the elderly: interaction and contribution to the rehabilitation strategies. Neurophysiol. Clin. Neurophysiol. 44, 95-107. https://doi.org/10.1016/j.neucli.2013.10.129.

Borg, F.G., Laxåback, G., 2010. Entropy of balance-some recent results. J. Neuroeng. Rehabil. 7, 1. https://doi.org/10.1186/1743-0003-7-38.

Brauer, S.G., Burns, Y.R., Galley, P., 2000. A prospective study of laboratory and clinical measures of postural stability to predict community-dwelling fallers. J. Gerontol. A Biol. Sci. Med. Sci. 55, M469-M476. https://doi.org/10.1093/gerona/55.8.M469.
Brodie, M.A., Coppens, M.J., Ejupi, A., Gschwind, Y.J., Annegarn, J., Schoene, D., Wieching, R., Lord, S.R., Delbaere, K., 2017. Comparison between clinical gait and daily-life gait assessments of fall risk in older people. Geriatr. Gerontol. Int. 17, 2274-2282. https://doi.org/10.1111/ggi.12979.

Buatois, S., Gueguen, R., Gauchard, G.C., Benetos, A., Perrin, P.P., 2006. Posturography and risk of recurrent falls in healthy non-institutionalized persons aged over 65 Gerontology 52, 345-352. https://doi.org/10.1159/000094983.

Bueno-Cavanillas, A., Padilla-Ruiz, F., Peinado-Alonso, C.A., 2000. Risk factors in falls among the elderly according to extrinsic and intrinsic precipitating causes. Eur. J. Epidemiol. 16, 848-858. https://doi.org/10.1023/A:1007636531965.

Carpenter, M., Frank, J., Silcher, C., Peysar, G., 2001. The influence of postural threat on the control of upright stance. Exp. Brain Res. 138, 210-218. https://doi.org/10. $1007 /$ s002210100681.

Caterino, J.M., Karaman, R., Arora, V., Martin, J.L., Hiestand, B.C., 2009. Comparison of balance assessment modalities in emergency department elders: a pilot cross-sectional observational study. BMC Emerg. Med. 9. https://doi.org/10.1186/1471227X-9-19.

Chiari, L., Cappello, A., Lenzi, D., Della Croce, U., 2000. An improved technique for the extraction of stochastic parameters from stabilograms. Gait Posture 12, 225-234. https://doi.org/10.1016/S0966-6362(00)00086-2.

Conn, V.S., Valentine, J.C., Cooper, H.M., Rantz, M.J., 2003. Grey literature in metaanalyses. Nurs. Res. 52, 256-261. https://doi.org/10.1097/00006199-200307000 00008.

da Costa, B.R., Rutjes, A.W.S., Mendy, A., Freund-Heritage, R., Vieira, E.R., 2012. Can falls risk prediction tools correctly identify fall-prone elderly rehabilitation in patients? A systematic review and meta-analysis. PLoS One 7, e41061. https://doi. org/10.1371/journal.pone.0041061.

Datta, A., Datta, R., Elkins, J., 2018. What factors predict falls in older adults living in nursing homes: a pilot study. J. Funct. Morphol. Kinesiol. 4, 3. https://doi.org/10 3390/jfmk4010003.

Deandrea, S., Bravi, F., Turati, F., Lucenteforte, E., La Vecchia, C., Negri, E., 2013. Risk factors for falls in older people in nursing homes and hospitals. A systematic review and meta-analysis. Arch. Gerontol. Geriatr. 56, 407-415. https://doi.org/10.1016/j. archger. 2012.12.006.

Delignières, D., Torre, K., Bernard, P.-L., 2011. Transition from persistent to anti-persistent correlations in postural sway indicates velocity-based control. PLoS Comput. Biol. 7, e1001089. https://doi.org/10.1371/journal.pcbi.1001089.

Deschamps, T., Le Goff, C.G., Berrut, G., Cornu, C., Mignardot, J.-B., 2016. A decision model to predict the risk of the first fall onset. Exp. Gerontol. 81, 51-55. https://doi. org/10.1016/j.exger.2016.04.016.

Downs, S.H., Black, N., 1998. The feasibility of creating a checklist for the assessment of the methodological quality both of randomised and non-randomised studies of health care interventions. J. Epidemiol. Community Health 52, 377-384.

Downs, S., Marquez, J., Chiarelli, P., 2013. The Berg Balance Scale has high intra-and inter-rater reliability but absolute reliability varies across the scale: a systematic review. J. Physiother. 59, 93-99.

Doyle, T.L., Newton, R.U., Burnett, A.F., 2005. Reliability of traditional and fractal dimension measures of quiet stance center of pressure in young, healthy people. Arch. Phys. Med. Rehabil. 86, 2034-2040. https://doi.org/10.1016/j.apmr.2005.05.014.

Doyle, R.J., Hsiao-Wecksler, E.T., Ragan, B.G., Rosengren, K.S., 2007. Generalizability of center of pressure measures of quiet standing. Gait Posture 25, 166-171. https://doi. org/10.1016/j.gaitpost.2006.03.004.

Dueñas, L., Balasch i Bernat, M., Mena del Horno, S., Aguilar-Rodríguez, M., Alcántara, E., 2016. Development of predictive models for the estimation of the probability of suffering fear of falling and other fall risk factors based on posturography parameters in community-dwelling older adults. Int. J. Ind. Ergon. 54, 131-138. https://doi.org/ 10.1016/j.ergon.2016.05.009.

Duque, J., Labruna, L., Cazares, C., Ivry, R.B., 2014. Dissociating the influence of response selection and task anticipation on corticospinal suppression during response preparation. Neuropsychologia 65, 287-296. https://doi.org/10.1016/j. neuropsychologia.2014.08.006.

Gates, S., Smith, L.A., Fisher, J.D., Lamb, S.E., et al., 2008. Systematic review of accuracy of screening instruments for predicting fall risk among independently living older adults. J. Rehabil. Res. Dev. 45, 1105-1116.

Gerdhem, P., Ringsberg, K.A.M., Åkesson, K., Obrant, K.J., 2005. Clinical history and biologic age predicted falls better than objective functional tests. J. Clin. Epidemiol. 58, 226-232. https://doi.org/10.1016/j.jclinepi.2004.06.013.

Gilfriche, P., Deschodt-Arsac, V., Blons, E., Arsac, L.M., 2018. Frequency-specific fractal analysis of postural control accounts for control strategies. Front. Physiol. 9. https:// doi.org/10.3389/fphys.2018.00293.

Goble, D.J., Coxon, J.P., Wenderoth, N., Van Impe, A., Swinnen, S.P., 2009. Proprioceptive sensibility in the elderly: degeneration, functional consequences and plastic-adaptive processes. Neurosci. Biobehav. Rev. 33, 271-278. https://doi.org/ 10.1016/j.neubiorev.2008.08.012.

Golriz, S., Hebert, J.J., Foreman, K.B., Walker, B.F., 2012. The reliability of a portable clinical force plate used for the assessment of static postural control: repeated measures reliability study. Chiropr. Man. Therap. 20, 14. https://doi.org/10.1186/2045709X-20-14.

HAS, 2007. Analyse de la posture statique et/ou dynamique sur plate-forme de force (posturographie) (No. CEQP005). Service évaluation des actes professionnels, France.

HAS, 2009. Évaluation et prise en charge des personnes âgées faisant des chutes répétées.

Hewson, D.J., Singh, N.K., Snoussi, H., Duchene, J., 2010. Classification of elderly as fallers and non-fallers using Centre of Pressure velocity. IEEE 3678-3681. https:// doi.org/10.1109/IEMBS.2010.5627649.

Higgins, J.P., Thompson, S.G., Deeks, J.J., Altman, D.G., 2003. Measuring inconsistency in meta-analyses. BMJ Br. Med. J. 327, 557. 
Hijmans, J.M., Geertzen, J.H.B., Dijkstra, P.U., Postema, K., 2007. A systematic review of the effects of shoes and other ankle or foot appliances on balance in older people and people with peripheral nervous system disorders. Gait Posture 25, 316-323. https:// doi.org/10.1016/j.gaitpost.2006.03.010.

Ho, C.Y., Bendrups, A.P., 2002. Ankle reflex stiffness during unperceived perturbation of standing in elderly subjects. J. Gerontol. A Biol. Sci. Med. Sci. 57, B344-B350. https://doi.org/10.1093/gerona/57.9.B344.

Horak, F.B., 1987. Clinical measurement of postural control in adults. Phys. Ther. 67, 1881-1885. https://doi.org/10.1093/ptj/67.12.1881.

Horak, F.B., 2006. Postural orientation and equilibrium: what do we need to know about neural control of balance to prevent falls? Age Ageing 35, ii7-ii11. https://doi.org/ 10.1093/ageing/afl077.

Howcroft, J., Kofman, J., Lemaire, E.D., 2013. Review of fall risk assessment in geriatric populations using inertial sensors. J. Neuroeng. Rehabil. 10, 91. https://doi.org/10. 1186/1743-0003-10-91.

Howcroft, J., Lemaire, E.D., Kofman, J., McIlroy, W.E., 2017. Elderly fall risk prediction using static posturography. PLoS One 12, e0172398. https://doi.org/10.1371/ journal.pone.0172398.

Hur, P., 2011. Quantification of the Human Postural Control System to Perturbations.

Hur, P., Kang, H.G., Lipsitz, L.A., Hsiao-Wecksler, E.T., 2009a. Invariant Density Analysis Of Postural Sway And Prospective Fall Risk In Community-Dwellering Elderly. 33rd Annual Meeting of the Amercan Society of Biomechanics.

Hur, P., Kang, H.G., Lipsitz, L.A., Hsiao-Wecksler, E.T., 2009b. Fall risk estimation of Community-dwellering elderly using invariant density analysis. In: Presented at the 34th Annual Meeting of the American Society of Biomechanics. Brown University.

Iaboni, A., Banez, C., Lam, R., Jones, S.A., Maki, B.E., Liu, B.A., Flint, A.J., 2015. Depression and outcome of fear of falling in a falls prevention program. Am. J. Geriatr. Psychiatry 23, 1088-1097. https://doi.org/10.1016/j.jagp.2015.02.006.

Institut national de la santé et de la recherche médicale (Inserm), 2015. Activité physique et prévention des chutes chez les personnes âgées. Rapport. (No. 978-2-85598920-5). INSERM.

James, M.K., Robitsek, R.J., Saghir, S.M., Gentile, P.A., Ramos, M., Perez, F., 2018. Clinical and non-clinical factors that predict discharge disposition after a fall. Injury 49, 975-982. https://doi.org/10.1016/j.injury.2018.02.014.

Jeka, J., Kiemel, T., Creath, R., Horak, F., Peterka, R., 2004. Controlling human upright posture: velocity information is more accurate than position or acceleration. J. Neurophysiol. 92, 2368-2379. https://doi.org/10.1152/jn.00983.2003.

Jeter, P.E., Wang, J., Gu, J., Barry, M.P., Roach, C., Corson, M., Yang, L., Dagnelie, G., 2015. Intra-session test-retest reliability of magnitude and structure of center of pressure from the Nintendo Wii Balance Board ${ }^{T M}$ for a visually impaired and normally sighted population. Gait Posture 41, 482-487. https://doi.org/10.1016/j. gaitpost.2014.11.012.

Johansson, J., Nordström, A., Gustafson, Y., Westling, G., Nordström, P., 2017. Increased postural sway during quiet stance as a risk factor for prospective falls in communitydwelling elderly individuals. Age Ageing 46, 964-970. https://doi.org/10.1093/ ageing/afx083.

Kamińska, M., Brodowski, J., Karakiewicz, B., 2015. Fall risk factors in communitydwelling elderly depending on their physical function, cognitive status and symptoms of depression. Int. J. Environ. Res. Public Health 12, 3406-3416. https://doi.org/10. 3390/ijerph120403406.

Kellogg International Work Group, 1987. The prevention of falls in later life. A report of the Kellogg International Work Group on the Prevention of Falls by the Elderly. Dan. Med. Bull. 34 (Suppl 4), 1-24.

King, G.W., Abreu, E.L., Kelly, P.J., Brotto, M., 2019. Neural control of postural sway: relationship to strength measures in young and elderly adults. Exp. Gerontol. 118, 39-44. https://doi.org/10.1016/j.exger.2019.01.005.

Kinney, J.M., 2004. Nutritional frailty, sarcopenia and falls in the elderly. Curr. Opin. Clin. Nutr. Metab. Care 7, 15-20. https://doi.org/10.1097/00075197-20040100000004.

König Ignasiak, N., Habermacher, L., Taylor, W.R., Singh, N.B., 2017. Cortical contribution to linear, non-linear and frequency components of motor variability control during standing. Front. Hum. Neurosci. 11, 548. https://doi.org/10.3389/fnhum. 2017.00548.

Kouzaki, M., Masani, K., 2012. Postural sway during quiet standing is related to physiological tremor and muscle volume in young and elderly adults. Gait Posture 35, 11-17. https://doi.org/10.1016/j.gaitpost.2011.03.028.

Kręcisz, K., Kuczyński, M., 2018. Attentional demands associated with augmented visual feedback during quiet standing. PeerJ 6, e5101. https://doi.org/10.7717/peerj.5101.

Kurz, I., Oddsson, L., Melzer, I., 2013. Characteristics of balance control in older persons who fall with injury - a prospective study. J. Electromyogr. Kinesiol. 23, 814-819. https://doi.org/10.1016/j.jelekin.2013.04.001.

Lacour, M., Bernard-Demanze, L., Dumitrescu, M., 2008. Posture control, aging, and attention resources: models and posture-analysis methods. Neurophysiol. Clin. Neurophysiol. 38, 411-421. https://doi.org/10.1016/j.neucli.2008.09.005.

Lafond, D., 2006. Reliability of center of pressure measures of postural steadiness. Arch. Phys. Med. Rehabil. 87, 308. https://doi.org/10.1016/j.apmr.2005.11.012.

Lafond, D., Corriveau, H., Hébert, R., Prince, F., 2004. Intrasession reliability of center of pressure measures of postural steadiness in healthy elderly people. Arch. Phys. Med. Rehabil. 85, 896-901. https://doi.org/10.1016/j.apmr.2003.08.089.

Lajoie, Y., Gallagher, S.P., 2004. Predicting falls within the elderly community: comparison of postural sway, reaction time, the Berg balance scale and the Activitiesspecific Balance Confidence (ABC) scale for comparing fallers and non-fallers. Arch. Gerontol. Geriatr. 38, 11-26. https://doi.org/10.1016/S0167-4943(03)00082-7.

Lajoie, Y., Girard, A., Guay, M., 2002. Comparison of the reaction time, the Berg Scale and the ABC in non-fallers and fallers. Arch. Gerontol. Geriatr. 35, 215-225.

Landi, F., Liperoti, R., Russo, A., Giovannini, S., Tosato, M., Capoluongo, E., Bernabei, R.,
Onder, G., 2012. Sarcopenia as a risk factor for falls in elderly individuals: results from the ilSIRENTE study. Clin. Nutr. 31, 652-658. https://doi.org/10.1016/j.clnu. 2012.02.007.

Langley, F.A., Mackintosh, S.F.H., ApplSc, B., 2007. Functional Balance Assessment of Older Community Dwelling Adults: A Systematic Review of the Literature. pp. 11.

Laughton, C.A., Slavin, M., Katdare, K., Nolan, L., Bean, J.F., Kerrigan, D.C., Phillips, E., Lipsitz, L.A., Collins, J.J., 2003. Aging, muscle activity, and balance control: physiologic changes associated with balance impairment. Gait Posture 18, 101-108. https://doi.org/10.1016/S0966-6362(02)00200-X.

Le Mouel, C., Brette, R., 2017. Mobility as the purpose of postural control. Front. Comput. Neurosci. 11, 67. https://doi.org/10.3389/fncom.2017.00067.

Lee, J.S., Hurley, M.J., Carew, D., Fisher, R., Kiss, A., Drummond, N., 2007. A randomized clinical trial to assess the impact on an emergency response system on anxiety and health care use among older emergency patients after a fall. Acad. Emerg. Med. 14, 301-308. https://doi.org/10.1197/j.aem.2006.11.017.

Leveille, S.G., Kiel, D.P., Jones, R.N., Roman, A., Hannan, M.T., Sorond, F.A., Kang, H.G., Samelson, E.J., Gagnon, M., Freeman, M., Lipsitz, L.A., 2008. The MOBILIZE Boston Study: design and methods of a prospective cohort study of novel risk factors for falls in an older population. BMC Geriatr. 8. https://doi.org/10.1186/1471-2318-8-16.

Li, Z., Liang, Y.-Y., Wang, L., Sheng, J., Ma, S.-J., 2016. Reliability and validity of center of pressure measures for balance assessment in older adults. J. Phys. Ther. Sci. 28, 1364.

Li, K.Z.H., Bherer, L., Mirelman, A., Maidan, I., Hausdorff, J.M., 2018. Cognitive involvement in balance, gait and dual-tasking in aging: a focused review from a neuroscience of aging perspective. Front. Neurol. 9. https://doi.org/10.3389/fneur. 2018.00913.

Lima, C.A., Ricci, N.A., Nogueira, E.C., Perracini, M.R., 2018. The Berg Balance Scale as a clinical screening tool to predict fall risk in older adults: a systematic review. Physiotherapy. https://doi.org/10.1016/j.physio.2018.02.002.

Lin, D., Seol, H., Nussbaum, M.A., Madigan, M.L., 2008. Reliability of COP-based postural sway measures and age-related differences. Gait Posture 28, 337-342. https://doi. org/10.1016/j.gaitpost.2008.01.005.

Lindemann, U., Scheible, S., Sturm, E., Eichner, B., Ring, C., Najafi, B., Aminian, K., Nikolaus, T., Becker, C., 2003. Elevated heels and adaptation to new shoes in frail elderly women. Z. Gerontol. Geriatr. 36, 29-34. https://doi.org/10.1007/s00391003-0133-x.

Lovecchio, N., Zago, M., Perucca, L., Sforza, C., 2016. Short-term repeatability of stabilometric assessments. Journal of Motor Behavior 0 1-6. https://doi.org/10.1080/ 00222895.2016.1152225.

Mahboobin, A., Loughlin, P.J., Redfern, M.S., 2008. A Model-Based Approach to Attention and Sensory Integration in Postural Control of Older Adults. pp. 11.

Maki, B.E., 1993. Biomechanical approach to quantifying anticipatory postural adjustments in the elderly. Med. Biol. Eng. Comput. 31, 355-362.

Maki, B.E., Holliday, P.J., Topper, A.K., 1991. Fear of falling and postural performance in the elderly. J. Gerontol. 46, M123-31. https://doi.org/10.1093/geronj/46.4.M123.

Maki, B.E., Holliday, P.J., Topper, A.K., 1994. A prospective study of postural balance and risk of falling in an ambulatory and independent elderly population. J. Gerontol. 49, M72-M84. https://doi.org/10.1093/geronj/49.2.M72.

Malini, F.M., Lourenço, R.A., Lopes, C.S., 2016. Prevalence of fear of falling in older adults, and its associations with clinical, functional and psychosocial factors: the Frailty in Brazilian Older People-Rio de Janeiro Study: fear of falling: FIBRA-RJ study. Geriatr. Gerontol. Int. 16, 336-344. https://doi.org/10.1111/ggi.12477.

Mancini, M., Horak, F.B., 2010. The relevance of clinical balance assessment tools to differentiate balance deficits. Eur. J. Phys. Rehabil. Med. 46, 239.

Maranesi, E., Merlo, A., Fioretti, S., Zemp, D.D., Campanini, I., Quadri, P., 2016. A statistical approach to discriminate between non-fallers, rare fallers and frequent fallers in older adults based on posturographic data. Clin. Biomech. 32, 8-13. https://doi. org/10.1016/j.clinbiomech.2015.12.009.

Masani, K., 2003. Importance of body sway velocity information in controlling ankle extensor activities during quiet stance. J. Neurophysiol. 90, 3774-3782. https://doi. org/10.1152/jn.00730.2002.

McMichael, K.A., Vander Bilt, J., Lavery, L., Rodriguez, E., Ganguli, M., 2008. Simple balance and mobility tests can assess falls risk when cognition is impaired. Geriatr. Nurs. (Minneap) 29, 311-323.

Melzer, I., Kurz, I., Oddsson, L.I.E., 2010. A retrospective analysis of balance control parameters in elderly fallers and non-fallers. Clin. Biomech. 25, 984-988. https://doi. org/10.1016/j.clinbiomech.2010.07.007.

Merlo, A., Zemp, D., Zanda, E., Rocchi, S., Meroni, F., Tettamanti, M., Recchia, A., Lucca, U., Quadri, P., 2012. Postural stability and history of falls in cognitively able older adults: the Canton Ticino study. Gait Posture 36, 662-666. https://doi.org/10.1016/ j.gaitpost.2012.06.016.

Mertes, G., Baldewijns, G., Dingenen, P.-J., Croonenborghs, T., Vanrumste, B., 2015. Automatic Fall Risk Estimation Using the Nintendo Wii Balance Board. SCITEPRESS Science and and Technology Publications, pp. 75-81. https://doi.org/10.5220/ 0005208700750081.

Moghadam, M., Ashayeri, H., Salavati, M., Sarafzadeh, J., Taghipoor, K.D., Saeedi, A., Salehi, R., 2011. Reliability of center of pressure measures of postural stability in healthy older adults: effects of postural task difficulty and cognitive load. Gait Posture 33, 651-655. https://doi.org/10.1016/j.gaitpost.2011.02.016.

Moher, D., Liberati, A., Tetzlaff, J., Altman, D.G., PRISMA Group, 2009. Preferred reporting items for systematic reviews and meta-analyses: the PRISMA statement. J. Clin. Epidemiol. 62, 1006-1012. https://doi.org/10.1016/j.jclinepi.2009.06.005.

Montero-Odasso, M., Verghese, J., Beauchet, O., Hausdorff, J.M., 2012. Gait and cognition: a complementary approach to understanding brain function and the risk of falling. Journal of the American Geriatrics Society n/a-n/a. https://doi.org/10.1111/ j.1532-5415.2012.04209.x. 
Muir, S.W., Berg, K., Chesworth, B., Klar, N., Speechley, M., 2010. Quantifying the magnitude of risk for balance impairment on falls in community-dwelling older adults: a systematic review and meta-analysis. J. Clin. Epidemiol. 63, 389-406. https://doi.org/10.1016/j.jclinepi.2009.06.010.

Muir, J.W., Kiel, D.P., Hannan, M., Magaziner, J., Rubin, C.T., 2013. Dynamic parameters of balance which correlate to elderly persons with a history of falls. PLoS One 8 e70566. https://doi.org/10.1371/journal.pone.0070566.

Murphy, J., Isaacs, B., 1982. The post-fall syndrome. A study of 36 elderly patients. Gerontology 28, 265-270.

Nandi, T., Fisher, B.E., Hortobágyi, T., Salem, G.J., 2018. Increasing mediolateral standing sway is associated with increasing corticospinal excitability, and decreasing M1 inhibition and facilitation. Gait Posture 60, 135-140. https://doi.org/10.1016/j. gaitpost.2017.11.021.

Nardone, A., Schieppati, M., 2010. The role of instrumental assessment of balance in clinical decision making. Eur. J. Phys. Rehabil. Med. 46, 221-237.

Nelson-Wong, E., Appell, R., McKay, M., Nawaz, H., Roth, J., Sigler, R., Third, J., Walker, M., 2012. Increased fall risk is associated with elevated co-contraction about the ankle during static balance challenges in older adults. Eur. J. Appl. Physiol. 112, 1379-1389. https://doi.org/10.1007/s00421-011-2094-x.

Ozdemir, R.A., Contreras-Vidal, J.L., Paloski, W.H., 2018. Cortical control of upright stance in elderly. Mech. Ageing Dev. 169, 19-31. https://doi.org/10.1016/j.mad. 2017.12.004.

Pajala, S., Era, P., Koskenvuo, M., Kaprio, J., Törmäkangas, T., Rantanen, T., 2008. Force platform balance measures as predictors of indoor and Outdoor Falls in communitydwelling women aged 63-76 years. J. Gerontol. A Biol. Sci. Med. Sci. 63, 171-178. https://doi.org/10.1093/gerona/63.2.171.

Palmieri, R.M., Ingersoll, C.D., Stone, M.B., Krause, B.A., 2002. Center-of-pressure parameters used in the assessment of postural control. J. Sport Rehabil. 11, 51-66.

Panzer, V.P., Wakefield, D.B., Hall, C.B., Wolfson, L.I., 2011. Mobility assessment: sensitivity and specificity of measurement sets in older adults. Arch. Phys. Med. Rehabil. 92, 905-912. https://doi.org/10.1016/j.apmr.2011.01.004.

Papegaaij, S., Taube, W., Hogenhout, M., Baudry, S., Hortob $\tilde{A}_{i g y i}$, T., 2014. Age-related decrease in motor cortical inhibition during standing under different sensory conditions. Front. Aging Neurosci. 6. https://doi.org/10.3389/fnagi.2014.00126.

Park, J.W., Jung, M., Kweon, M., 2014. The mediolateral CoP parameters can differentiate the fallers among the community-dwelling elderly population. J. Phys. Ther. Sci. 26, 381-384.

Pereira, C.L.N., Vogelaere, P., Baptista, F., 2008. Role of physical activity in the prevention of falls and their consequences in the elderly. Eur. Rev. Aging Phys. Act. 5, 51-58. https://doi.org/10.1007/s11556-008-0031-8.

Perell, K.L., Nelson, A., Goldman, R.L., Luther, S.L., Prieto-Lewis, N., Rubenstein, L.Z., 2001. Fall risk assessment measures: an analytic review. J. Gerontol. A Biol. Sci. Med. Sci. 56, M761-M766. https://doi.org/10.1093/gerona/56.12.M761.

Piirtola, M., Era, P., 2006. Force platform measurements as predictors of falls among older people - a review. Gerontology 52, 1-16. https://doi.org/10.1159/000089820.

Prabhakaran, K., Gogna, S., Pee, S., Samson, D.J., Con, J., Latifi, R., 2019. Falling again? Falls in geriatric adults-risk factors and outcomes associated with recidivism. J. Surg. Res. https://doi.org/10.1016/j.jss.2019.10.041. S0022480419307711.

Prieto, T.E., Myklebust, J.B., Hoffmann, R.G., Lovett, E.G., Myklebust, B.M., 1996 Measures of postural steadiness: differences between healthy young and elderly adults. IEEE Trans. Biomed. Eng. 43, 956-966.

Qiu, H., Xiong, S., 2015. Center-of-pressure based postural sway measures: reliability and ability to distinguish between age, fear of falling and fall history. Int. J. Ind. Ergon. 47, 37-44. https://doi.org/10.1016/j.ergon.2015.02.004.

Quijoux, Flavien, Truong, Charles, Vienne-Jumeau, Aliénor, Oudre, Laurent, BertinHugault, François, Zawieja, Philippe, Lefèvre, Marie, Vidal, Pierre-Paul, Ricard, Damien, 2020. Meta-analysis parameters computation: a Python approachto facilitate the crossing of experimental conditions. arXiv(math) Submitted for publication.

Quijoux, F., Vienne-Jumeau, A., Bertin-Hugault, F., Lefèvre, M., Zawieja, P., Vidal, P.-P., Ricard, D., 2019. Center of pressure characteristics from quiet standing measures to predict the risk of falling in older adults: a protocol for a systematic review and metaanalysis. Syst. Rev. 8, 232. https://doi.org/10.1186/s13643-019-1147-9.

Rajagopalan, R., Litvan, I., Jung, T.-P., 2017. Fall prediction and prevention systems: recent trends, challenges, and future research directions. Sensors 17, 2509. https:// doi.org/10.3390/s17112509.

Rasku, J., Juhola, M., Garcia, M., Harris, T., Launer, L., Eiriksdottir, G., Siggeirsdottir, K., Jonsson, P., Hoffman, H.J., Petersen, H., et al., 2012. Evaluation of the postura stability of elderly persons using time domain signal analysis. J. Vestib. Res. 22, 243-252.

Resnick, B., Nahm, E.S., Zhu, S., Brown, C., An, M., Park, B., Brown, J., 2014. The Impact of Osteoporosis, Falls, Fear of Falling, and Efficacy Expectations on Exercise Among Community-Dwelling Older Adults. Orthop. Nurs. 33, 277-286. https://doi.org/10. 1097/NOR.0000000000000084.

Ricci, N.A., de Faria Figueiredo Gonçalves, D., Coimbra, A.M.V., Coimbra, I.B., 2009. Sensory interaction on static balance: a comparison concerning the history of falls of community-dwelling elderly. Geriatr. Gerontol. Int. 9, 165-171. https://doi.org/10. 1111/j.1447-0594.2009.00516.x.

Rubenstein, L.Z., 2006. Falls in older people: epidemiology, risk factors and strategies for prevention. Age Ageing 35, ii37-ii41. https://doi.org/10.1093/ageing/afl084.

Rubenstein, L.Z., Josephson, K.R., Robbins, A.S., 1994. Falls in the nursing home. Ann. Intern. Med. 121, 442-451. https://doi.org/10.7326/0003-4819-121-6-199409150 00009.

Ruhe, A., Fejer, R., Walker, B., 2010. The test-retest reliability of centre of pressure measures in bipedal static task conditions - a systematic review of the literature. Gait Posture 32, 436-445. https://doi.org/10.1016/j.gaitpost.2010.09.012.

Ryan, R., Hill, S., 2016. How to GRADE the Quality of the Evidence.
Salsabili, H., Bahrpeyma, F., Esteki, A., Karimzadeh, M., Ghomashchi, H., 2013. Spectral characteristics of postural sway in diabetic neuropathy patients participating in balance training. J. Diabetes Metab. Disord. 12, 29. https://doi.org/10.1186/22516581-12-29.

Santos, B.R., Delisle, A., Larivière, C., Plamondon, A., Imbeau, D., 2008. Reliability of centre of pressure summary measures of postural steadiness in healthy young adults. Gait Posture 27, 408-415. https://doi.org/10.1016/j.gaitpost.2007.05.008.

Scherder, E., Eggermont, L., Swaab, D., van Heuvelen, M., Kamsma, Y., de Greef, M., van Wijck, R., Mulder, T., 2007. Gait in ageing and associated dementias; its relationship with cognition. Neurosci. Biobehav. Rev. 31, 485-497. https://doi.org/10.1016/j. neubiorev.2006.11.007.

Schmid, M., Conforto, S., Camomilla, V., Cappozzo, A., D'alessio, T., 2002. The sensitivity of posturographic parameters to acquisition settings. Med. Eng. Phys. 24, 623-631.

Schoene, D., Wu, S.M.-S., Mikolaizak, A.S., Menant, J.C., Smith, S.T., Delbaere, K., Lord, S.R., 2013. Discriminative ability and predictive validity of the timed up and go test in identifying older people who fall: systematic review and meta-analysis. J. Am. Geriatr. Soc. 61, 202-208. https://doi.org/10.1111/jgs.12106.

Schubert, P., Kirchner, M., Schmidtbleicher, D., Haas, C.T., 2012. About the structure of posturography: sampling duration, parametrization, focus of attention (part I). J. Biomed. Sci. Eng. 5, 496-507. https://doi.org/10.4236/jbise.2012.59062.

Schumann, T., Redfern, M.S., Furman, J.M., El-Jaroudi, A., Chaparro, L.F., 1995. Timefrequency analysis of postural sway. J. Biomech. 28, 603-607.

Seidler, R.D., Martin, P.E., 1997. The effects of short term balance training on the postural control of older adults. Gait Posture 6, 224-236. https://doi.org/10.1016/S09666362(97)00012-X.

Seidler, R.D., Bernard, J.A., Burutolu, T.B., Fling, B.W., Gordon, M.T., Gwin, J.T., Kwak, Y., Lipps, D.B., 2010. Motor control and aging: links to age-related brain structural, functional, and biochemical effects. Neurosci. Biobehav. Rev. 34, 721-733. https:// doi.org/10.1016/j.neubiorev.2009.10.005.

Sheridan, P.L., Hausdorff, J.M., 2007. The role of higher-level cognitive function in gait: executive dysfunction contributes to fall risk in alzheimer's disease. Dement. Geriatr. Cogn. Disord. 24, 125-137. https://doi.org/10.1159/000105126.

Shumway-Cook, A., Woollacott, M., Kerns, K.A., Baldwin, M., 1997. The effects of two types of cognitive tasks on postural stability in older adults with and without a history of falls. J. Gerontol. A Biol. Sci. Med. Sci. 52, M232-240.

Shumway-Cook, A., Brauer, S., Woollacott, M., 2000. Predicting the probability for falls in community-dwelling older adults using the timed up \& go Test. Phys. Ther. 80, 896-903.

Siren, A., Amilon, A., Larsen, G.K., Mehlsen, L., 2019. The promise of assistive technology in institutionalized old age care: economic efficiency, improved working conditions, and better quality of care? Disabil. Rehabil. Assist. Technol. 1-7. https://doi.org/10. 1080/17483107.2019.1659862.

Soangra, R., Lockhart, T.E., 2012. Determination of stabilogram diffusion analysis coefficients and invariant density analysis parameters to understand postural stability associated with standing on anti-fatigue mats. Biomed. Sci. Instrum. 48, 415.

Srulijes, K., Mack, D.J., Klenk, J., Schwickert, L., Ihlen, E.A.F., Schwenk, M., Lindemann, U., Meyer, M., K.C., S, Hobert, M.A., Brockmann, K., Wurster, I., Pomper, J.K., Synofzik, M., Schneider, E., Ilg, U., Berg, D., Maetzler, W., Becker, C., 2015. Association between vestibulo-ocular reflex suppression, balance, gait, and fall risk in ageing and neurodegenerative disease: protocol of a one-year prospective follow-up study. BMC Neurol. 15. https://doi.org/10.1186/s12883-015-0447-5.

Stel, V.S., Smit, J.H., Pluijm, S.M.F., Lips, P., 2003. Balance and mobility performance as treatable risk factors for recurrent falling in older persons. J. Clin. Epidemiol. 56, 659-668. https://doi.org/10.1016/S0895-4356(03)00082-9.

Stroup, D.F., Berlin, J.A., Morton, S.C., Olkin, I., Williamson, G.D., Rennie, D., Moher, D., Becker, B.J., Sipe, T.A., Thacker, S.B., 2000. Meta-analysis of observational studies in epidemiology: a proposal for reporting. Meta-analysis of Observational Studies in Epidemiology (MOOSE) group. JAMA 283, 2008-2012.

Suzuki, Y., Geyer, H., 2018. A neuro-musculo-skeletal model of human standing combining muscle-reflex control and virtual model control. In: 2018 40th Annual International Conference of the IEEE Engineering in Medicine and Biology Society (EMBC). Presented at the 2018 40th Annual International Conference of the IEEE Engineering in Medicine and Biology Society (EMBC). IEEE, Honolulu, HI. pp. 5590-5593. https://doi.org/10.1109/EMBC.2018.8513543.

Suzuki, M., Fujisawa, H., Suzuki, H., Kawakami, S., Murakami, K., Miki, C., 2017. Frequency analysis of the center of pressure in tandem stance in community-dwelling elderly. J. Phys. Ther. Sci. 29, 828-831.

Swanenburg, J., de Bruin, E.D., Favero, K., Uebelhart, D., Mulder, T., 2008. The reliability of postural balance measures in single and dual tasking in elderly fallers and nonfallers. BMC Musculoskelet. Disord. 9. https://doi.org/10.1186/1471-2474-9-162.

Swanenburg, J., de Bruin, E.D., Uebelhart, D., Mulder, T., 2010. Falls prediction in elderly people: a 1-year prospective study. Gait Posture 31, 317-321. https://doi.org/10. 1016/j.gaitpost.2009.11.013.

Talbot, L.A., Musiol, R.J., Witham, E.K., Metter, E.J., 2005. Falls in young, middle-aged and older community dwelling adults: perceived cause, environmental factors and injury. BMC Public Health 5, 86. https://doi.org/10.1186/1471-2458-5-86.

Tallon, G., Blain, H., Seigle, B., Bernard, P.L., Ramdani, S., 2013. Dynamical and stabilometric measures are complementary for the characterization of postural fluctuations in older women. Gait Posture 38, 92-96. https://doi.org/10.1016/j.gaitpost. 2012.10.021.

The Joanna Briggs Institute, 2015. The Joanna Briggs Institute Reviewers' Manual 2015: the Systematic Review of Studies of Diagnostic Test Accuracy. The Joanna Briggs Institute.

Tinetti, M.E., Speechley, M., Ginter, S.F., 1988. Risk factors for falls among elderly persons living in the community. N. Engl. J. Med. 319, 1701-1707. https://doi.org/10 1056/NFJM198812293192604. 
Topper, A.K., Maki, B.E., Holliday, P.J., 1993. Are Activity-Based Assessments of Balance and Gait in the Elderly Predictive of Risk of Falling and/or Type of Fall? J. Am. Geriatr. Soc. 41, 479-487. https://doi.org/10.1111/j.1532-5415.1993.tb01881.x.

Truong, C., Barrois-Müller, R., Moreau, T., Provost, C., Vienne-Jumeau, A., Moreau, A. Vidal, P.-P., Vayatis, N., Buffat, S., Yelnik, A., Ricard, D., Oudre, L., 2019. A data set for the study of human locomotion with inertial measurements units. Image Process. Line 9, 381-390. https://doi.org/10.5201/ipol.2019.265.

Tuunainen, E., Rasku, J., Jäntti, P., Pyykkö, I., 2014. Risk factors of falls in community dwelling active elderly. Auris Nasus Larynx 41, 10-16. https://doi.org/10.1016/j. anl.2013.05.002

van Emmerik, R.E.A., van Wegen, E.E.H., 2002. On the functional aspects of variability in postural control. Exerc. Sport Sci. Rev. 30, 177-183. https://doi.org/10.1097 00003677-200210000-00007.

Vassallo, M., Poynter, L., Sharma, J.C., Kwan, J., Allen, S.C., 2008. Fall risk-assessment tools compared with clinical judgment: an evaluation in a rehabilitation ward. Age Ageing 37, 277-281. https://doi.org/10.1093/ageing/afn062.

Vellas, B.J., Wayne, S.J., Romero, L.J., Baumgartner, R.N., Garry, P.J., 1997. Fear of falling and restriction of mobility in elderly fallers. Age Ageing 26, 189-193. https:// doi.org/10.1093/ageing/26.3.189.

Vette, A.H., Sayenko, D.G., Jones, M., Abe, M.O., Nakazawa, K., Masani, K., 2017. Ankle muscle co-contractions during quiet standing are associated with decreased postural steadiness in the elderly. Gait Posture 55, 31-36. https://doi.org/10.1016/j.gaitpost. 2017.03.032.

Visser, J.E., Carpenter, M.G., van der Kooij, H., Bloem, B.R., 2008. The clinical utility of posturography. Clin. Neurophysiol. 119, 2424-2436. https://doi.org/10.1016/j. clinph.2008.07.220.

Watt, A.A., Clark, C., Williams, J.M., 2018. Differences in sit-to-stand, standing sway and stairs between community-dwelling fallers and non-fallers: a review of the literature. Phys. Ther. Rev. 23, 273-290. https://doi.org/10.1080/10833196.2018.1470748.

WHO, 2008. Global Report on Falls Prevention in Older Age. World Health Organization, pp. 47.

Wihlborg, A., Englund, M., Åkesson, K., Gerdhem, P., 2015. Fracture predictive ability of physical performance tests and history of falls in elderly women: a 10-year prospective study. Osteoporos. Int. 26, 2101-2109. https://doi.org/10.1007/s00198015-3106-1.

Woollacott, M., Shumway-Cook, A., 2002. Attention and the control of posture and gait: a review of an emerging area of research. Gait Posture 16, 1-14.

Yamada, M., Takechi, H., Mori, S., Aoyama, T., Arai, H., 2013. Global brain atrophy is associated with physical performance and the risk of falls in older adults with cognitive impairment: global brain atrophy and falls. Geriatr. Gerontol. Int. 13, 437-442. https://doi.org/10.1111/j.1447-0594.2012.00927.x.

Zampieri, C., Salarian, A., Carlson-Kuhta, P., Aminian, K., Nutt, J.G., Horak, F.B., 2010 The instrumented timed up and go test: potential outcome measure for disease modifying therapies in Parkinson's disease. J. Neurol. Neurosurg. Psychiatr. 81, 171-176. https://doi.org/10.1136/jnnp.2009.173740.

Zhavoronkov, A., Mamoshina, P., Vanhaelen, Q., Scheibye-Knudsen, M., Moskalev, A., Aliper, A., 2019. Artificial intelligence for aging and longevity research: recent advances and perspectives. Ageing Res. Rev. 49, 49-66. https://doi.org/10.1016/j.arr 2018.11.003. 